\title{
The rat STSL locus: characterization, chromosomal assignment, and genetic variations in sitosterolemic hypertensive rats Hongwei Yu1 ${ }^{1}$, Bhaswati Pandit ${ }^{1}$, Eric Klett ${ }^{1}$, Mi-Hye Lee ${ }^{1}$, Kangmo Lu${ }^{1}$, Khalil Helou 2,3, Ikuo Ikeda4, Nami Egashira4, Masao Sato4, Richard Klein ${ }^{1}$, Ashok Batta ${ }^{5}$, Gerald Salen ${ }^{5}$ and Shailendra B Patel*1
}

\begin{abstract}
Address: ${ }^{1}$ Division of Endocrinology, Diabetes and Medical Genetics, Medical University of South Carolina, STR 541, 114 Doughty Street, Charleston, SC 29403, USA, ${ }^{2}$ Genetics Branch, Center for Cancer Research, National Cancer, Institute/NIH, Bethesda, Maryland 20892, USA, ${ }^{3}$ Department of Oncology, Institute of Selected Clinical Sciences, Goteborg University, SE 413 45, Gothenburg, Sweden, ${ }^{4}$ Laboratory of Nutrition Chemistry, Department of Bioscience and Biotechnology, Faculty of Agriculture, Graduate School Kyushu University, Fukuoka, 812-8581, Japan and ${ }^{5}$ Research Service and Medical Service, Department of Veterans Affairs Medical Center, East Orange, NJ, USA
\end{abstract}

Email: HongweiYu - yuh@musc.edu; Bhaswati Pandit - pandit@musc.edu; Eric Klett - klettel@musc.edu; Mi-Hye Lee - leemih@musc.edu; Kangmo Lu - luk@musc.edu; Khalil Helou - khalil.helou@oncology.gu.se; Ikuo Ikeda - Iikeda@agr.kyushu-u.ac.jp; Nami Egashira - Iikeda@agr.kyushu-u.ac.jp; Masao Sato - Iikeda@agr.kyushu-u.ac.jp; Richard Klein - kleinrl@musc.edu; Ashok Batta - salenge@umdnj.edu; Gerald Salen - salenge@undnj.edu; Shailendra B Patel* - patelsb@musc.edu

* Corresponding author

Published: 3 June 2003

BMC Cardiovascular Disorders 2003, 3:4

This article is available from: http://www.biomedcentral.com/|47|-226|/3/4

(C) 2003 Yu et al; licensee BioMed Central Ltd. This is an Open Access article: verbatim copying and redistribution of this article are permitted in all media for any purpose, provided this notice is preserved along with the article's original URL.

\section{Abstract}

Background: Elevated plant sterol accumulation has been reported in the spontaneously hypertensive rat (SHR), the stroke-prone spontaneously hypertensive rat (SHRSP) and the WistarKyoto (WKY) rat. Additionally, a blood pressure quantitative trait locus (QTL) has been mapped to rat chromosome 6 in a New Zealand genetically hypertensive rat strain (GH rat). ABCG5 and ABCG8 (encoding sterolin-I and sterolin-2 respectively) have been shown to be responsible for causing sitosterolemia in humans. These genes are organized in a head-to-head configuration at the STSL locus on human chromosome $2 \mathrm{p} 2 \mathrm{I}$.

Methods: To investigate whether mutations in Abcg5 or Abcg8 exist in SHR, SHRSP, WKY and GH rats, we initiated a systematic search for the genetic variation in coding and non-coding region of Abcg5 and Abcg8 genes in these strains. We isolated the rat cDNAs for these genes and characterized the genomic structure and tissue expression patterns, using standard molecular biology techniques and FISH for chromosomal assignments.

Results: Both rat Abcg5 and Abcg8 genes map to chromosome band $6 q 12$. These genes span $\sim 40$ $\mathrm{kb}$ and contain $\mathrm{I} 3$ exons and 12 introns each, in a pattern identical to that of the STSL loci in mouse and man. Both Abcg5 and Abcg8 were expressed only in liver and intestine. Analyses of DNA from SHR, SHRSP, GH, WKY, Wistar, Wistar King A (WKA) and Brown Norway (BN) rat strains revealed a homozygous $G$ to $T$ substitution at nucleotide 1754 , resulting in the coding change Gly583Cys in sterolin-I only in rats that are both sitosterolemic and hypertensive (SHR, SHRSP and WKY).

Conclusions: The rat STSL locus maps to chromosome $6 q 12$. A non-synonymous mutation in Abcg5, Gly583Cys, results in sitosterolemia in rat strains that are also hypertensive (WKY, SHR and SHRSP). Those rat strains that are hypertensive, but not sitosterolemic (e.g. GH rat) do not have mutations in Abcg5 or Abcg8. This mutation allows for expression and apparent apical targeting of $A b c g 5$ protein in the intestine. These rat strains may therefore allow us to study the pathophysiological mechanisms involved in the human disease of sitosterolemia. 


\section{Background}

The human disorder of sitosterolemia, also known as phytosterolemia (MIM 210250), is an autosomal recessive disorder characterized by the marked elevation of plasma phytosterols e.g. $\beta$-sitosterol, campesterol and stigmasterol $[1,2]$. Hypercholesterolemia primarily during childhood, accelerated atherosclerosis in some adult patients leading to premature death, as well a hemolytic anaemia, arthralgias and tendon and tuberous xanthoma formations are other clinical features. Studies have shown that the sitosterolemic patients hyperabsorb all sterols (cholesterol and phytosterols) and fail to excrete phytosterols into bile [3-7]. Positional mapping of the STSL locus to human chromosome 2p21 led to the identification of two genes, ATP binding cassette (ABC) half-transporters G5 and G8 that were mutated in affected individuals [8-12]. The protein products of these two genes (sterolin- 1 and sterolin-2 respectively) are thought to form heterodimers to constitute a functional transporter, based primarily on the genetic evidence that affected individuals are either completely mutated in sterolin-1 or sterolin-2, but not both [12]. More recently, evidence from in vitro expression of these proteins has been presented that these two proteins co-immunoprecipitate, supporting this conclusion [13]. ABCG5 and ABCG8 appear to be present in all mammalian genomes examined to date and are highly conserved between species, indicating that these genes may have a similar function in other species. In order to identify naturally occurring animal models of sitosterolemia, we previously reported a screen of 20 in-bred mouse strains [14]. This screen showed considerable genetic variation at these loci in the mouse strains, but none of these strains exhibited sitosterolemia. However, a literature search revealed that a few strains of rats, studied primarily for investigation of hypertension and stroke, have been reported to be sitosterolemic as well $[15,16]$. We hypothesised that these rat strains may be mutated in either $A b c g 5$ or $A b c g 8$. Tissue (and plasma) plant sterol levels in the Wistar Kyoto (WKY) rat, the spontaneously hypertensive rat (SHR) and the stroke-prone spontaneously hypertensive rat (SHRSP) were significantly higher than in Wistar and WKA rats fed either a regular chow diet or diets that have higher plant sterols and these were correlated with increased death, or red cell hemolysis etc. [15-22]. Dietary sterol absorption rates were increased, with a decrease in sterol excretion [16], characteristics similar to that observed in sitosterolemic patients.

In this study, we report the gene structure organisation, cDNA and tissue expression patterns of rat Abcg5 and Abcg8. Using fluorescence in situ hybridization, the rat STSL locus was assigned to the chromosomal 6q12. Interestingly, a cluster of 2 blood pressure (BP) quantitative trait loci (QTL) in $(\mathrm{GH} \times \mathrm{BN}) \mathrm{F} 2$ with LOD scores 4.63 (tail BP) and 6.82 (intra-arterial BP) has also been reported to map to rat chromosome 6 between D6Mit3 and D6Mit12, an area containing the STSL locus. We interrogated this region for genetic variations and found a correlation between sitosterolemic strains and a missense mutation in $\mathrm{Abcg} 5$.

\section{Methods \\ DNA Samples of rat strains}

The DNA samples from the following rat strains were used: Sprague Dawley (SD, Charles River Laboratories, Wilmington, MA), Wistar (Sea: Wistar, Outbred, SPF, Seac Yoshitomi) and WKA (WKA/Sea, inbred, SPF, Seac Yoshitomi), WKY (WKY/NCrj, inbred, SPF, Charles River Japan, Kanagawa, Japan or Charles River, Wilmington, MA), SHR/Crl (Charles River, Wilmington, MA), SHRSP (SHRSP/Sea, inbred, SPF, Seac Yoshitomi, Fukuoka, Japan), GH and BN. The genomic DNAs from GH and BN rats were a kind gift from Dr. E. L Harris (New Zealand). The liver tissue genomic DNAs from SD, WKY and SHR rats were extracted by digestion overnight at $55^{\circ} \mathrm{C}$ in lysis buffer (10 mM Tris pH8.0, $100 \mathrm{mM} \mathrm{NaCl}, 50 \mathrm{mM}$ EDTA, $0.5 \%$ SDS and $0.2 \mathrm{mg} / \mathrm{ml}$ proteinase $\mathrm{K}$ ) followed by phenol-chloroform extraction and ethanol precipitation.

\section{Genomic analysis and determination of exon-intron boundaries}

Rat cDNAs for $A b c g 5$ and $A b c g 8$ were identified previously by amplification of these sequences from a Sprague Dawley rat enterocyte cDNA library, using primers located in areas conserved between mouse and human (Genbank AF312714 and AF351785 respectively). For Abcg5, the first PCR fragment was obtained by PCR using primers, ABCG5 F4, 5'-ATCCTCAAAGATGTCTCCTTGTAC-3', and ABCG5 R3, 5'-TCCTGACTCTCCTGGTCGCT-3'. For Abcg8 cDNA sequences, the primers, F11 5'-AGATGCTGGCCATCATAGGG-3' and R13 5'-GATGGAGAAGGTGAAGTTGCC-3', were used to amplify rat $A b c g 8$ cDNA fragments. These products were sequenced and used to design primers specific for rat CDNA and a rat intestinal cDNA library was screened by anchor PCR.

Direct sequencing of the PCR products led to the identification of rat cDNA sequence and allowed for design of rat specific primers (Table 1, see Additional file 1). Based upon the structure of mouse genes, putative rat-specific exonic primers were designed and used to amplify rat genomic regions as previously described. All PCR products were directly sequenced and both strands were sequenced as a routine. The complete rat genomic sequences have been deposited with GenBank (AY145899). 


\section{Chromosomal localisation by fluorescence in situ hybridi- zation (FISH)}

For FISH analysis, metaphase chromosomes were prepared from rat embryo fibroblasts. The cells were cultured in DMEM medium at $37^{\circ} \mathrm{C}$ for 2 days and treated with $0.05 \mu \mathrm{g} / \mathrm{ml}$ colcemid for $45 \mathrm{~min}$. The cells were harvested by mitotic shake-off and resuspended in $0.075 \mathrm{M} \mathrm{KCl}$ at room temperature for $10 \mathrm{~min}$. Fixation was carried out as described previously [23].

Fluorescence in situ hybridization (FISH) was performed essentially according to Pinkel et al [24] with minor modifications [25]. The rat sequences used for FISH labelling were amplified genomic DNA fragments (Abcg5 exons 610, primers RG5-F6 and RG5-R10, and Abcg8 exons 4-13, primers RG8-F4 and RG8-R13, Table 1, see Additional file $1)$. The two gene fragments were labelled separately with digoxigenin-11-dUTP (Boehringer Mannheim, Germany) by nick-translation (Life Technologies Inc., Gaithersburg, $\mathrm{MD}$ ). Appropriate length (50 to $500 \mathrm{bp}$ ) of the nick translated fragments was monitored by checking the nicktranslation products on a $1 \%$ agarose gel. The two gene fragments were precipitated separately using $800 \mathrm{ng}$ of labelled DNA with $20 \mu \mathrm{g}$ unlabeled rat $\mathrm{C}_{\mathrm{o}} \mathrm{t} 1$ DNA, which was included in order to suppress probe hybridization to repetitive sequences. The probe DNA mixtures were ethanol precipitated and dissolved in hybridization buffer ( 50 $\%$ formamide, $2 \times$ SSC, $10 \%$ dextran sulphate). After denaturation, the highly repetitive sequences in the probe mixture DNA were allowed to bind to the $\mathrm{C}_{\mathrm{o}} \mathrm{t} 1$ DNA (10 $\min$ at $37^{\circ} \mathrm{C}$ ). The probe mixtures were then applied to rat fibroblast metaphase chromosome slides (previously denatured at $73^{\circ} \mathrm{C}$ for $2 \mathrm{~min}$ in $70 \%$ formamide, $2 \times$ SSC). Hybridization was allowed to proceed in a moist chamber for $70 \mathrm{~h}$ at $37^{\circ} \mathrm{C}$. Subsequently, the slides were washed for $15 \mathrm{~min}$ at $45^{\circ} \mathrm{C}$ in $55 \%$ formamide, $2 \times \mathrm{SSC}$, and then in $2 \times \operatorname{SSC}(\mathrm{pH} 7.0)$ at $43^{\circ} \mathrm{C}$ for $9 \mathrm{~min}$. The labelled probe molecules were detected with rhodamine anti-digoxigenin (Oncor, Inc., Gaithersburg, MD) and the slides were washed 3 times in PBS and $0.1 \%$ Nonidet NP40. Finally, chromosome spreads were counterstained with 4,6-diamino-2-phenylindole (DAPI, $0.5 \mu \mathrm{g} / \mathrm{ml}$ ) in an antifade solution (Vectashield ${ }^{\circledR}$, Vector Laboratories, Inc., Burlingame, CA). The images were captured using the LEICA DM RXA in combination with the Q-FISH software for microphotography.

\section{Tissue expression of Abcg5 and Abcg8}

A rat multiple tissue Northern blot (Origene Technologies, Rockville, MD) containing immobilised poly $\mathrm{A}^{+}$ mRNA from Sprague Dawley rat was used. Rat sterolin cDNA probes were labelled and hybridization and washing steps were performed as described previously [26]. Total tissue RNAs were extracted from multiple tissues from a Sprague Dawley rat using Trizol reagent as described previously. Random hexamers were used as primers for reverse transcription of $2 \mu \mathrm{g}$ of rat RNA from the multiple tissues. The primers were annealed to template at $25^{\circ} \mathrm{C}$ for $10 \mathrm{~min}$, and the reaction were incubated at $53^{\circ} \mathrm{C}$ for $1 \mathrm{~h}$ in the presence of Superscript Reverse transcriptase, $5 \mathrm{mM}$ dNTP mix and RN'ase Out inhibitor. The rat Abcg5-specific primers (RG5c-F1 and RG5Fc-R1), Abcg8-specific primers (RG8c-F1 and RG8c-R1) and $\beta$ actin primers (sense: 5'-CTACGTCGCCCTGGACTTCGAGC-3', antisense: 5'-GATGGAGCCGCCGATCCACACGG-3') were used for further PCR amplification (an initial denaturation at $94^{\circ} \mathrm{C}$ for $3 \mathrm{~min}, 35$ cycles of PCR amplification with each cycle consisting of $30 \mathrm{~min}$ at $94^{\circ} \mathrm{C}, 45 \mathrm{~s}$ at $60^{\circ} \mathrm{C}$, and $2 \mathrm{~min}$ at $72^{\circ} \mathrm{C}$, followed by an extension step of $72^{\circ} \mathrm{C}$ for $5 \mathrm{~min}$ ). The resultant PCR products were gel-purified and sequenced.

\section{Real-Time PCR}

For quantitation, real-time PCR was employed. Primers used were based upon previously published mouse primer sets $[27,28]$, or designed using MacVector from cDNA sequences between exons, avoiding the amplification of potentially contaminating genomic DNA in the total RNA sample (Table 2). Samples of total RNA (2 $\mu \mathrm{g})$ from rat livers were reverse transcribed according to the SuperScript' First-Strand Synthesis System (Invitrogen, Carlsbad, CA) using random hexamers with a final volume of $20 \mu$ l. Real-time PCR was performed on a PE Biosystems GeneAmp 5700 sequence Detection System (Forest City, CA). Standard reaction volume was $10 \mu \mathrm{l}$ and contained 1X QuantiTect SYBR Green PCR master mix (Qiagen, Valencia, CA), 0.002 U AmpErase UNG enzyme (PE Biosystems, Forest City, CA), $0.7 \mu$ l of cDNA template and $100-500 \mathrm{nM}$ of oligonucleotide primers. Initial steps of RT-PCR were 2 minutes at $50^{\circ} \mathrm{C}$ for UNG erase activation, followed by a 15 minute hold at $95^{\circ} \mathrm{C}$. Cycles $(\mathrm{n}=$ 40) consisted of a 15 second melt at $95^{\circ} \mathrm{C}$, followed by a 1 minute annealing/extension at $60^{\circ} \mathrm{C}$. The final step was a $60^{\circ} \mathrm{C}$ incubation for 1 minute. All reactions were performed in triplicate. Threshold cycle (CT) analysis of all samples was set at 0.5 relative fluorescence units.

The relative amounts of $A b c g 5, A b c g 8$, Cyp7a1, HMG-CoA reductase, and Srebp-2 message from rat liver samples used in real-time RT-PCR were normalised to GAPDH expression levels to compensate for variations in input RNA amounts. The data were analysed using the comparative threshold cycle method (CT) method. Briefly, the CT values were averaged, from triplicate determinations, defining a $\Delta$-CT value calculated by taking the average CT of the gene of interest and subtracting it from the average CT of GAPDH. The $\Delta \Delta$-CT was calculated by subtracting the average $\Delta$-CT(calibrator) values from the $\Delta$-CT(sample). The relative quantification was then calculated by the expression 2 (Average $\Delta \Delta \mathrm{CT}$ ). The mRNA quantity for the 
Table I: Sequence of the rat $A b c g 5$ and rat $A b c g 8$ intron-exon boundaries

\begin{tabular}{|c|c|c|c|c|}
\hline Exon & Exon size (bp) & Sequence of exon-intron boundaries & Intron & Intron size (bp) \\
\hline & & Abcg5 & & \\
\hline I & 145 & TCAGCGTCAGgtaaggggacccca...gatttcctttaaagCAACCGTGTC & I & 612 \\
\hline 2 & $|2|$ & GGTAGCTCAGgtaagcgcctcgag...ttgtcgcccctgagGCTCAGGGAA & 2 & 5000 \\
\hline 3 & 136 & CСTCCTGCAGgtgggcgtgtccct...cccctttcctgcagAGCGATGTCT & 3 & 86 \\
\hline 4 & 98 & CGACAAGAAGgtacttttagttaa...tgtgtctcttacagGTAGAGGCAG & 4 & 2320 \\
\hline 5 & 132 & CAGGACCCCAgtaagtgggacaca...ttctttgctggcagAGGTCATGAT & 5 & 1317 \\
\hline 6 & 139 & GCTCTTCCACgtaagggaacaccc...tgtggtccaatcagCACTTCGACA & 6 & 901 \\
\hline 7 & 130 & GATTTCTACAgtaagtgcattttt...ggggaaacttttagTGGACTTGAC & 7 & 699 \\
\hline 8 & 213 & TTCTCCTGAGgtaagagccttgga...catttggttttcagGAGAGTAACG & 8 & 104 \\
\hline 9 & 205 & GTGAACCTCTgtaagtgcctgtgt...gccttccatgccagTTCCCATGCT & 9 & 836 \\
\hline 10 & 138 & TGTGTTACTGgtaaggtggtgtcc...tcgtgtttttctagGACTCTGGGC & 10 & 2810 \\
\hline II & 185 & GATTTATCAGgtaagaagaaatga...ttctctttcttaagAAACATAGAA & 11 & 4500 \\
\hline 12 & 112 & TTCACTTGTGgtaagtatcctatt...cttctccttggcagGTGGCTCCAA & 12 & 1705 \\
\hline \multirow[t]{2}{*}{13} & 193 & & & \\
\hline & & Abcg8 & & \\
\hline I & 62 & GGATGCTTCAgtgagtgacctagt...ctgtctcccagcagAGCCTCCAGG & 1 & 3190 \\
\hline 2 & 101 & CACCTACCAGgtaggggcacatgc...acaatctgctctagGGTGGCACAT & 2 & 623 \\
\hline $2 b$ & 66 & ATCTGAATCTgtgagttcccggtt...acctctccccacagGTGGACATGG & $2 b$ & 1114 \\
\hline 3 & 156 & GGGAGCGCAGgtaccacagagacc...ttctgggtttgcagGCTGCGGGAG & 3 & 3000 \\
\hline 4 & 240 & AGACAAACGGgtaaccagtgggct...cagcctgccctcagGTGGAAGACG & 4 & 442 \\
\hline 5 & 130 & TGGAACCCAGgtgaggcctgggaa...gcgataccccccagGAATCCTCAT & 5 & 86 \\
\hline 6 & 269 & GACTTCTACGgtgagtgagtaaag...tcttctgcttgcagTGGACTTGAC & 6 & 2200 \\
\hline 7 & 162 & ATGCAGTCAGgtactgagagaagc...actgttcccaacagCCAGACCCTC & 7 & 81 \\
\hline 8 & 79 & CCCTGATCCGgtaaatcaacctct...ttcctttctttcagTCGTCAGATT & 8 & 1234 \\
\hline 9 & 202 & GTCTCCAAATgtgagtgtcacccg...tcccccatctccagCACTCGGAGC & 9 & 165 \\
\hline 10 & 73 & CTTTGCCAAGgtcagggccaggag...gctgtgctttgcagGTCCTCGGTG & 10 & 552 \\
\hline 11 & 267 & CTGTGGATAGgtgaggcctgcccc....cttgctgtcttcagTACCTGCATG & 11 & 1205 \\
\hline 12 & 127 & CGGAGACGCGgtacgtagcgaggg...gtctgtgtccgcagATGGTCACTG & 12 & 87 \\
\hline 13 & 134 & & & \\
\hline
\end{tabular}

Exon sequences are shown in uppercase letter; intron sequences are in lowercase. The underlined sequence at the donor and acceptor sites of Abcg8 intron I are identical to mouse.

calibrator (SD samples) is expressed as $1 \mathrm{X}$ sample and all other quantities are expressed as a fold difference relative to the calibrator (SD samples).

\section{Total membrane protein preparations}

Approximately $500 \mathrm{mg}$ of liver tissue cut into small pieces was homogenised in ice cold lysis buffer $(5 \mathrm{mM}$ TrispH7.5, $250 \mathrm{mM}$ sucrose with protease inhibitors PMSF, Leupeptin, Aprotinin) by a dounce homogenizer times 10 strokes. Samples were then subjected to centrifugation $1000 \mathrm{~g}$ for 10 minutes at $4^{\circ} \mathrm{C}$. The supernatant was saved. The pellet was resuspended and subjected to dounce homogenisation by 10 strokes, centrifuged at $1000 \mathrm{~g}$ for 10 minutes at $4{ }^{\circ} \mathrm{C}$ and this step was repeated once more. The supernatants from all three steps were pooled and subjected to ultracentrifugation at 100,000 g for $40 \mathrm{~min}$ utes at $4{ }^{\circ} \mathrm{C}$, and the pellet was resuspended in $25 \mathrm{mM}$ Tris-pH7.5, $150 \mathrm{mM} \mathrm{NaCl}, 0.1 \%$ TritonX-100 and $0.1 \%$ SDS, by passaging through a 25 -gauge needle. Membrane protein concentrations were determined by a colorimetric assay according to manufacturer's protocol (BioRad, Her- cules, CA) and $20 \mu \mathrm{g}$ of total membrane proteins resolved by $7.5 \%$ SDS acrylamide gel.

\section{Immunoblotting and Immunolocalization}

Proteins resolved by SDS-PAGE were transferred to nitrocellulose membranes and the membranes blocked for 2 hours in 5\% dry milk in PBS-T (Phosphate Buffered saline and $0.1 \%$ Tween 20 ). Blots were then probed with a primary rabbit anti-peptide (116-VNGCELRRDQFQDCCVSYLLQS-136) antibody against rat sterolin-1 (1:1000 dilution) overnight at $4^{\circ} \mathrm{C}$. The blot was washed once for 5 minutes in PBS-T, incubated with goat-anti-rabbit conjugated HRP (1:10000 dilution) for 1 hour, washed for 5 minutes in PBS-T and developed with Western Lightning Chemiluminescence Reagent Plus (PerkinElmer Life Sciences, Inc. Boston, MA).

Snap-frozen rat liver and intestine tissues were sectioned to $8 \mu \mathrm{m}$ thickness using a cryotome (Bright), air-dried for 30 min and keep at $-80^{\circ} \mathrm{C}$ until used. The slides were stained with hematoxylin. Fixation was performed by 
Table 2: Oligonucleotide primers used for real time PCR or rat sequences

\begin{tabular}{|c|c|c|c|}
\hline $\begin{array}{l}\text { Target } \\
\text { Gene }\end{array}$ & Primer Sequence & $\begin{array}{l}\text { Length of } \\
\text { Amplicon }\end{array}$ & $\begin{array}{l}\text { GenBank }^{\mathrm{TM}} \\
\text { accession no. }\end{array}$ \\
\hline Abcg5 & Forward: 5'-AGGCTCAGTTACAGGCTCAGAG-3' Reverse: 5'-GTCCCACTTCTGCTGGCATGAT & $118 \mathrm{bp}$ & $\mathrm{AF} 3127 \mid 4$ \\
\hline Abcg8 & Forward: 5'-CGTCAGATTTCCAATGACTTCCG-3' Reverse: 5'-TCCGTCCTCCAGTTCATAGTACA-3' & $241 \mathrm{bp}$ & AF35I785 \\
\hline Cyp7al & Forward: 5'-CAGGGAGATGCTCTGTGTTCA-3' Reverse: 5'-AGGCATACATCCCTTCCGTGA-3' & $121 \mathrm{bp}$ & NM_0I 2924 \\
\hline $\begin{array}{l}\text { HMG-CoA } \\
\text { Reductase }\end{array}$ & Forward: 5'-GAACTGAAACACGGGCATTGG-3' Reverse: 5'-ACGGCACGGAAAGAACCATAG-3' & 189 bp & $\times 55286$ \\
\hline Srebp-2 & $\begin{array}{l}\text { Forward: 5'-TGGAAGGAAGGTAGAGTAGGTGGG-3' Reverse: 5'-TTTTGTGGACTGCTTGGCT- } \\
\text { CAGGG-3' }\end{array}$ & 152 bp & AA90I364 \\
\hline GAPDH & Forward: 5'-TCAAGAAGGTGGTGAAGCAGGC-3' Reverse: 5'-GCATCAAAGGTGGAAGAATGGG-3' & $118 \mathrm{bp}$ & AFI06860 \\
\hline
\end{tabular}

incubating samples for 10 min with cooled methanol at $20^{\circ} \mathrm{C}$ and washed with PBS three times. The slides were treated with blocking solution $(10 \%$ goat serum in $0.1 \mathrm{M}$ glycine/PBS) for $30 \mathrm{~min} .$, primary antibody applied and incubated overnight at $4{ }^{\circ} \mathrm{C}$. The slides were washed with PBS and secondary antibody (goat-anti-rabbit FITC conjugated) was applied for 20-30 min at room temperature, washed and the signals captured and analyzed using an Olympus BX-50 microscope with Fluoview software. The fluorescent stained images were observed under blue filter excitation and capture excitation images at $488 \mathrm{~nm}$ wavelength.

\section{Nucleotide polymorphisms in Abcg5 and Abcg8 genes} Direct sequencing of PCR amplified genomic fragments was performed as described previously [11]. The 5' flanking region, all the exons and the 3'UTR region, as well as the introns of Abcg5 and Abcg8 with size less than $1 \mathrm{~Kb}$, were individually amplified using primers, as described in Table 1. The amplified PCR products were sequenced by the use of an automated capillary sequencer. The Sprague Dawley nucleotide sequence of Abcg5 and Abcg8 was regarded as wild-type. Comparisons to mammalian sterolins (GenBank accession Nos. AF312713, AF312714, AF312715, AF324494 AF324495, AF351785) as well as Fugu (GenBank No. CAAB01001529), was made using ClustalW [29].

\section{Results}

\section{Genomic organisation and chromosome mapping of the rat STSL locus}

Rat cDNA sequences for Abcg5 and Abcg8 were isolated and characterized as indicated in Methods. Based upon the known conservation between the murine and human STSL loci [14], we designed oligonucleotides in putative exonic regions and used PCR amplification of rat genomic region to characterise the genome organisation. Figure 1 shows a summary composite of the genomic organisation. The intron-exon boundary sequences are indicated in Table 2. In keeping with the human and mouse STSL loci, the rat $A b c g 5$ and $A b c g 8$ genes are arranged in a head-to- head configuration, with a distance of 379 bp separating their respective initiation codons. The exact start transcriptional sites for either gene has not been definitively established. Comparison of the DNA sequence of isolated cDNAs, as well as the polypeptide sequence with human and mouse sequences revealed a very high degree of homology $(>80 \%)$. To assign the chromosomal location, we performed FISH analyses, and we were able to unambiguously map the rat STSL locus to chromosome $6 \mathrm{q} 12$ (Fig. 2). There is specific labelling of both chromatids of both homologues of rat chromosome (RNO) 6 (Fig. 2A and $2 \mathrm{~B})$. Based on the DAPI-banding pattern the Abcg5 and $A b c g 8$ genes were sub-localized to RNO6q12. The STSL locus was mapped to the same position as shown by the diagrammatic representation of the rat Chr. 6 as shown in Fig. 2. The human ABCG5 and ABCG8 genes are present in a group of 18 genes ABCG5, ABCG8, SLC8A1, PRKR, GCKR, KHK, PPP1CB, APOB, POMC1, SDC1, $M Y C N, D D X 1, V S N L 1, R R M 2, O D C 1, I D 2, T P O$ and $A C P 1$ in the region HSA2p21-p25, and this group is also present on RNO6. Thus, the ABCG5 and ABCG8 genes fit into a group of genes that are syntenic both in HSA2 and in RNO6. A conserved segment between HSA2, RNO6, and MMU17 on RNO6q11-q16 has been demonstrated by Zoo-FISH analysis and gene mapping data, confirming this synteny [30-32].

\section{Expression patterns of rat Abcg5 and Abcg8 mRNAs}

Rat $A b c g 5$ and Abcg8 mRNA expression patterns were determined, using a commercial multiple tissue poly $\mathrm{A}^{+}$ Northern filter. Expression appeared mainly to be confined to the liver (Fig. 3A), with dominant transcripts sizes of $\sim 2.5 \mathrm{~kb}$ for $A b c g 5$ and of $\sim 4.5 \mathrm{~kb}$ for Abcg8. However, the poly $\mathrm{A}^{+} \mathrm{RNA}$ loaded onto this Northern blot has been adjusted to obtain an identical $\beta$-actin signal, and the intestinal RNA loaded may thus have less enterocyte RNA. Using a more sensitive RT-PCR analyses of RNA obtained from different tissues confirmed that rat Abcg5 and Abcg8 genes were expressed in both in the liver and small intestine, with a low level of expression in the colon (Fig. 3B). 


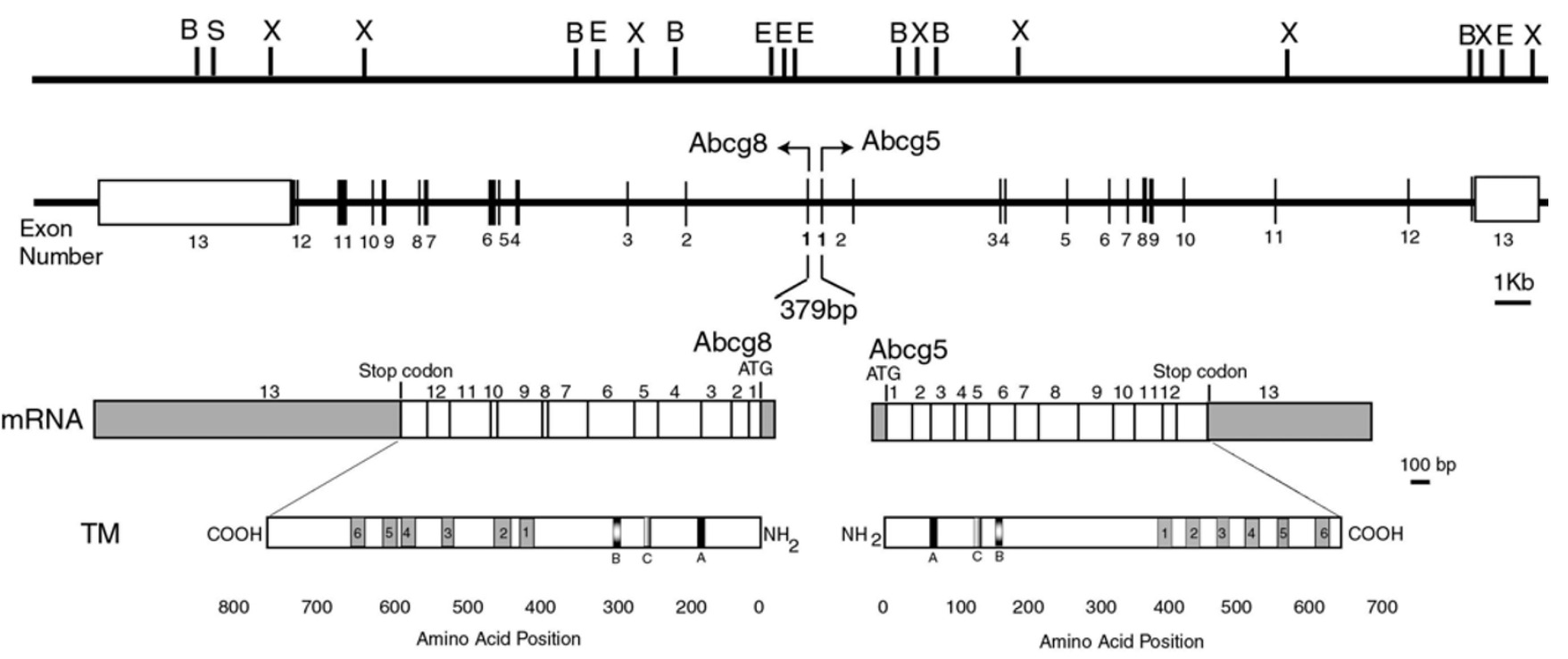

Figure I

Organisation of the rat Abcg5 and Abcg8 genes The top line indicates the restriction endonuclease map of the STSL locus; B, Bam HI; E, EcoRI; S, Sal I, X, Xbal. The second line indicates Abcg5 and Abcg8 gene organisation, with the vertical lines representing exons, numbered as shown. The 379 bp separating 5'ends of Abcg5 and Abcg8 is indicated. The direction of transcription of $A b c g 5$ and $A b c g 8$ is as indicated by the arrows, resulting in mRNAs indicated on the line below. The gray portions indicate the UTRs for $A b c g 5$ and $A b c g 8$. The polypeptides are depicted with the predicted transmembrane spanning regions, as well as the $A, B$ and $C$ Walker motifs, characteristic for the $A B C$ family of protein.

Additionally, while screening an enterocyte cDNA library for full length cDNAs using PCR, we consistently amplified two DNA products when using Abcg8 primers flanking exon 2; one of the expected size, and another very low copy product $\sim 60$ bases larger. Direct sequencing of these products confirmed both of these contained Abcg8 rat cDNA sequences, but the larger product contained a $66 \mathrm{bp}$ insertion, resulting in a predicted in-frame addition of 22 amino acids, between exons 2 and 3. To confirm that this insertion resulted from an alternatively spliced mRNA, we amplified and sequenced the intragenic region between exons 2 and 3 and identified a 66 bp exon (exon 2b), flanked by canonical splice-sites (see Table 1 and Fig. 4). We next screened total liver and intestinal RNA, using RTPCR, from SD, SHR and WKY rats (Fig. 4). In all samples a larger DNA fragment of low abundance was identified (Fig. 4) and direct sequencing showed that these fragments contained exon $2 \mathrm{~b}$ sequences (data not shown). It is not established whether these transcripts are a result of aberrant splicing, or are translated and code for a slightly larger sterolin-2. Careful interrogation of the mouse and human genomic sequences did not identify any homologous sequences, suggesting this is unique to the rat. Addi- tionally, both the mouse and human Abcg8 genes have alternatively spliced mRNA, involving a CAG repeat at exon 2 and exon 8 splice acceptor sites respectively $[12,14]$. However, despite the presence of such a repeat at the rat exon 2 splice acceptor site for Abcg8 (Table 1), none of the rat mRNAs showed any heterogeneity of splice-site selection at this site.

\section{Hypertensive rats have sitosterolemia and a mis-sense change in Abcg5}

A number of different groups have reported that genetically hypertensive strains of rats (SHR, SHRSP, WKY) have elevated levels of plasma sitosterol [15-22]. Although the WKY strain is not considered hypertensive, dietary alterations involving plant sterols appear to increase blood pressure in this strain [21]. We screened two commercially available hypertensive rats, as well as a 'genetically hypertensive' strain, GH, for plasma plant sterol levels and compared these to two control strains, Sprague-Dawley and Wistar (Table 3). Our analyses confirmed that WKY, and SHR are sitosterolemic on a chow diet, but neither the control strains, nor the GH rat showed any significant differences. 

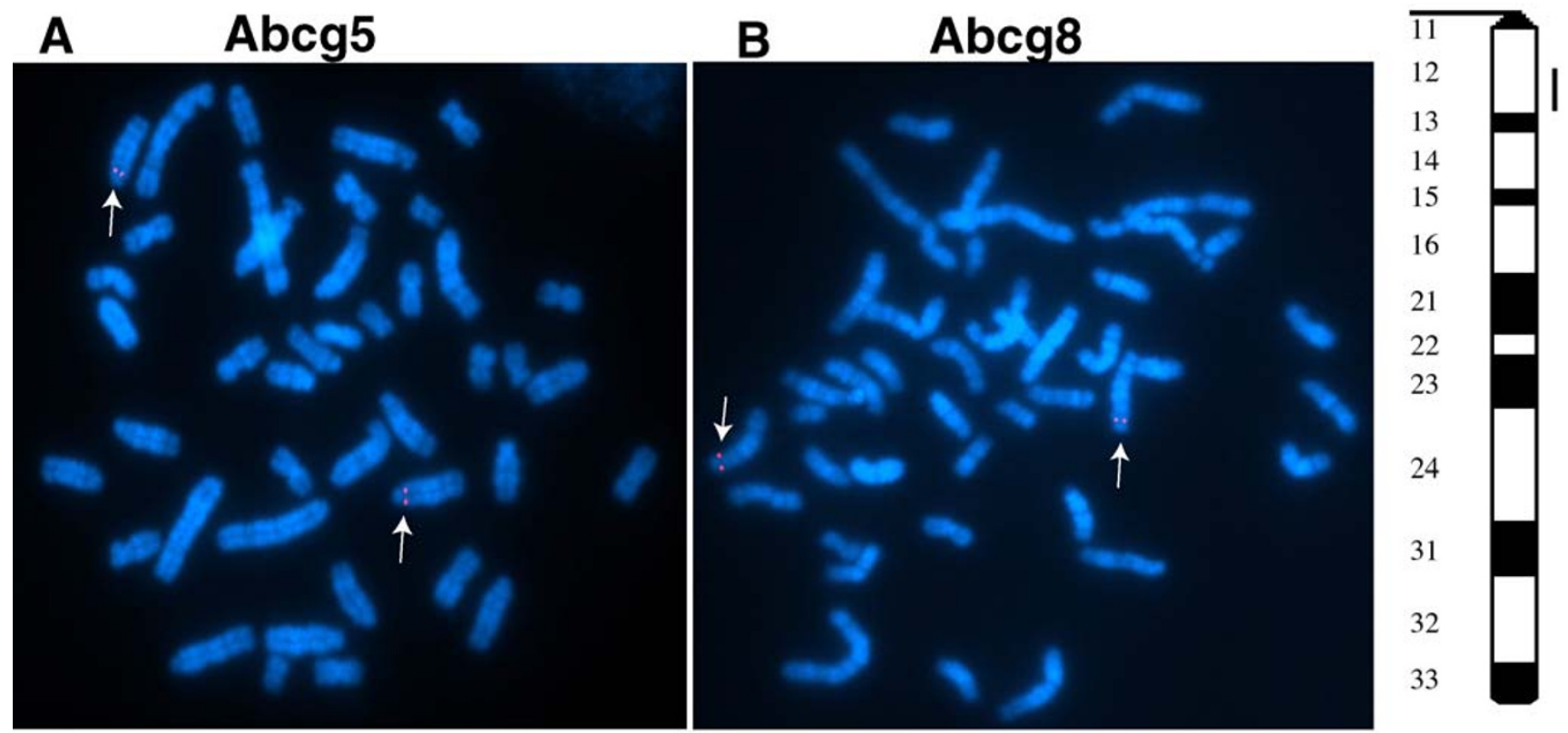

RNO6

Figure 2

Chromosomal mapping by FISH A representative photograph of the FISH analyses, shows the localisation of rat $A b c g 5$ (panel A) and Abcg8 (panel B) to both pairs of chromosome 6 in a metaphase spread (arrows). An ideogram of rat chromosome 6 showing the mapped position of both $A b c g 5$ and $A b c g 8$ genes (vertical bar) is shown at the right hand side.

To identify if alterations at the STSL locus could account for these observations, we amplified and directly sequenced Abcg5 and Abcg8 from Wistar, Sprague-Dawley, WKY, WKA, GH, SHR, and SHRSP rats. Table 4 shows a compilation of both coding and non-coding alterations detected. There were 24 polymorphic changes detected in Abcg5 and 14 polymorphic changes in Abcg8. However, only one non-synonymous nucleotide change, G1754T, resulting in a conservative cysteine substitution for glycine at amino acid 583 (Gly583Cys) in sterolin-1 was identified (Fig. 5A). This 'mutation' was only detected in SHR, SHRSP and WKY rats and was present in all of these strains as a homozygous change (Table 4 ). These hypertensive strains also shared uniquely 4 other nucleotide changes not present in the other strains (Table 4). These latter changes were confined to intronic areas and the 3'UTR region. Although the intronic changes are unlikely to alter the biology of these genes, the 3' UTR insertion in Abcg8 mRNA could be important, if message stability were affected. This possibility was not formally investigated.
The identified G1754T (Gly583Cys) missense mutation of the Abcg5 generates loss of a restriction site for Hae III after PCR amplification of exon 12, and this allowed a PCR-RFLP assay to further confirm the detected change (Figure 5B). Note that the DNA chosen from a single Wistar rat was heterozygous for almost all of these changes. The amino acid G583 is conserved between all known mammalian sterolin-1 proteins (Fig. 5C) and its alteration may have functional consequences, as it is also conserved in evolution, being conserved in the Fugu fish (Fig. 5C). Fugu sterolin-1 shows a 55\% homology to rat sterolin-1 at the amino acid level, and its gene structure is also organized in a similar fashion (data not shown). Currently, a gap in the Fugu genomic sequence has not been completed that may encode for exon 2. The complete Fugu STSL locus is available on-line (GenBank No. CAAB01001529).

In $A b c g 8$, a large insertional polymorphism was identified in exon 13, that resulted in the insertion of 143 nucleotides in the 3'UTR (*2099_2100ins143nt). WKY, SHR, 

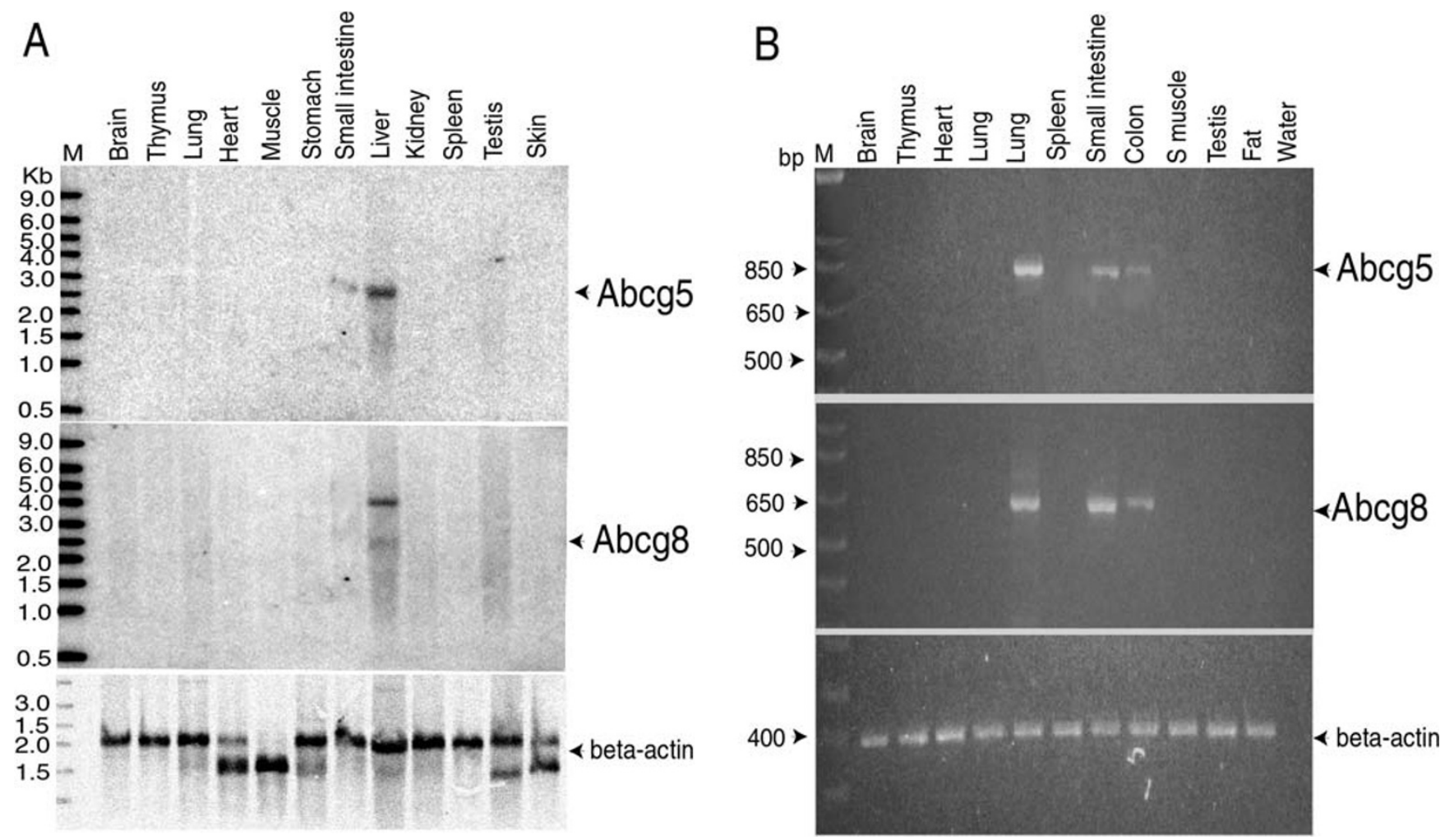

Figure 3

Expression analyses of rat Abcg5 and Abcg8 Panel A, Northern blot analyses of poly (A)+ RNA from a variety of rat tissues (see Materials and Methods) showed that expression of Abcg5 (top panel) and Abcg8 (middle panel) was confined mainly to liver. Panel B, RT-PCR analyses confirmed the liver expression pattern, but further showed that both Abcg5 and Abcg8 were also expressed in the small intestine and colon, but not in any other tissues screened. As a control, $\beta$-actin expression was used in both Northern and RT-PCR analyses.

SHRSP and GH rats are homozygous, Sprague Dawley and WKA strains wild-type and the Wistar sample heterozygous for this polymorphism (Fig. 6).

\section{Comparison of expression of Abcg5 and Abcg8 in hyper- tensive rat strains}

Expression levels of $A b c g 5$ and $A b c g 8$ in these rat strains were examined in two ways. For mRNA expression, quantitative real time PCR was utilised, and for protein, western blotting analyses, as well as immunohistochemistry was employed. Fig. 7 shows the results of the real time PCR assays of liver RNAs from fasted animals. Using GAPDH mRNA expression as a control, expression of Abcg5 and Abcg8 mRNAs appeared to be increased in liver from SHR compared to Sprague Dawley (Fig. 7), the message for Cyp7 a1 (except for Wistar and WKY) HMG CoA reductase, SR-B1, and SREBP-2 (except for SHR) were relatively unchanged. Interestingly, the message for LDL-R was reduced in both WKY and SHR livers.
To compare protein expression levels of the sterolins, we performed western blotting. A reliable antibody to sterolin-1 was available only and was used to probe liver microsomal lysates from Sprague Dawley, SHR and Wistar rats (Fig. 8). Although equal amounts of microsomal protein lysates were loaded from the livers of these different strains, we consistently observed that the protein expression patterns were always different between SHR and the control strains (Fig. 8, panel C, cf. tracks 5, 6 and $8)$. Thus, all of the data were normalised in one of two ways, either by using total microsomal protein, or by using the intensity of transferrin signal, after western blotting. Both of these methods gave consistent results and indicated that expression of Abcg5 was increased approximately 2-fold in the SHR but not the Wistar or SD (Fig. 8). To further assess if the mutant protein is mis-targeted, we performed immunolocalization, using an anti-peptide rabbit antibody, on various rat liver and intestinal sections (Fig. 9). We did not observe any differences between the staining patterns observed for the control rat strains 
A

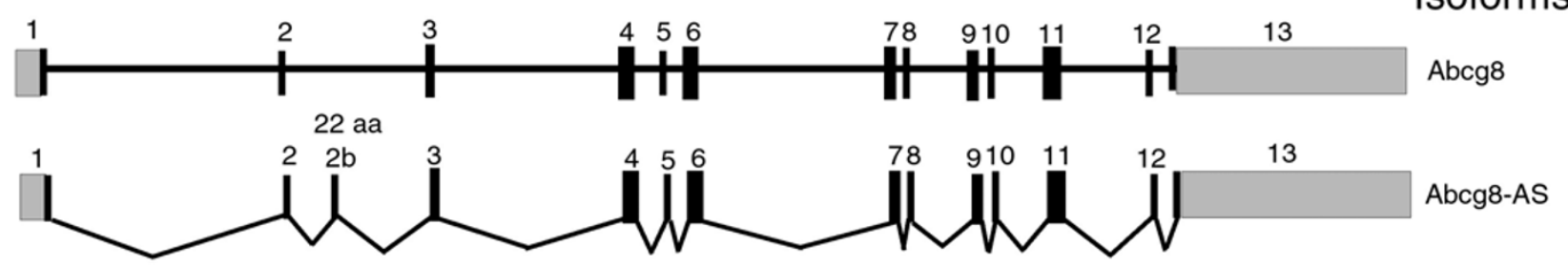

B
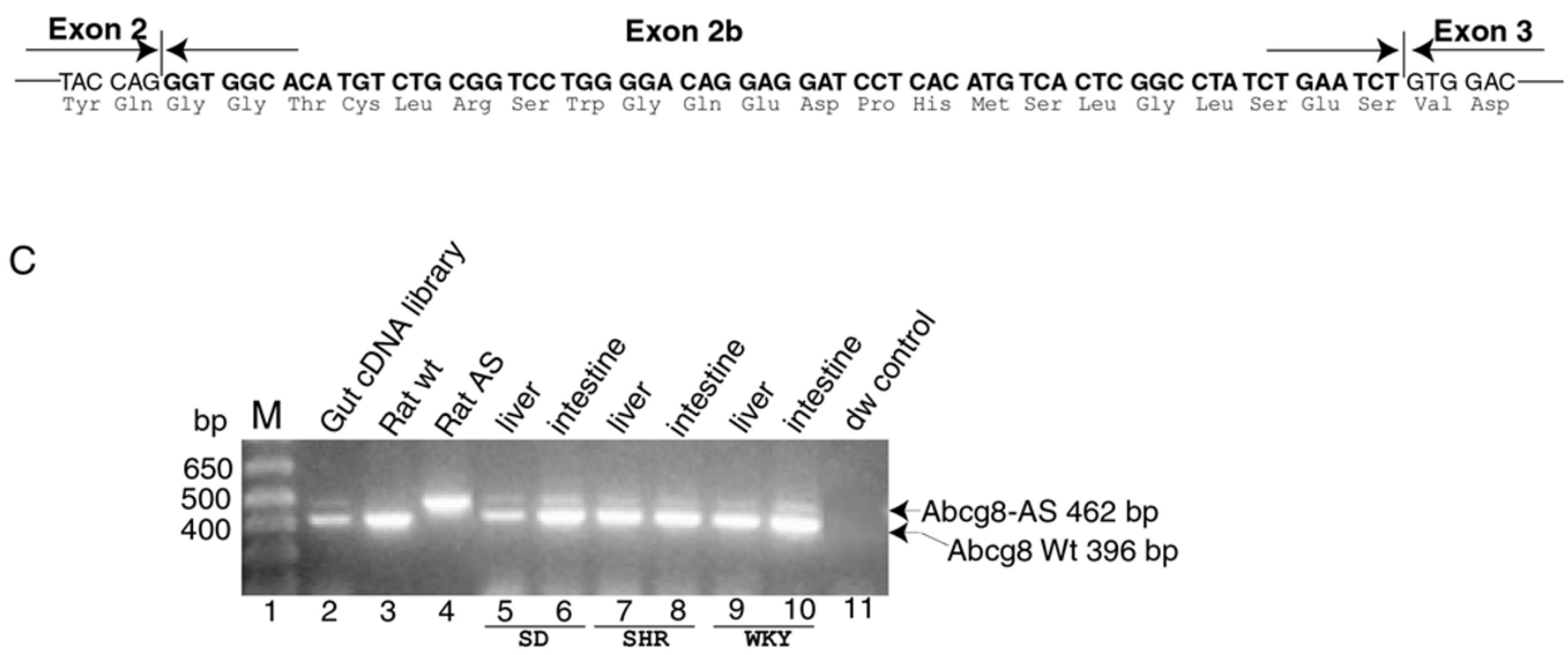

Figure 4

Alternative splicing of Abcg8 mRNA expression in SD, SHR and WKY rats by RT-PCR Panel A shows the gene organisation of $A b c g 8$, and below it the organisation of an alternatively spliced form detected by sequencing clones from a rat intestinal cDNA library (see Text). Panel $B$ shows that the effect of the inclusion of exon $2 b$ in the mRNA results in an in-frame addition of 22 amino acids. Total RNAs were prepared from liver and small intestine from SD, SHR and WKY rats maintained on a standard rodent chow diet and analysed by RT-PCR with primers (see Methods) based outside the alternatively spliced exon $2 \mathrm{~b}$. Direct amplification of a pooled cDNA library sample indicated a major DNA product of $396 \mathrm{bp}$, with a minor product of 462 bp, containing exon $2 \mathrm{~b}$. DNA products, using cloned wild type Abcg8 cDNA (wt) and alternatively spliced cDNA (AS) are shown in tracks 3 and 4 respectively. As can be seen, liver and intestine RNA from all three strains show a minor DNA product of $462 \mathrm{bp}$ (confirmed by sequencing) contained the insertion of exon $2 \mathrm{~b}$ sequences.

(Wistar or SD) and the mutant hypertensive strains (SHR, SHRSP). Interestingly, we observed a clear apical staining pattern for $A b c g 5$ in the intestine and this was not altered in the mutant strains (Fig. 9, panel B).

\section{Discussion}

Recent studies on ABC transporters have significantly advanced our understanding of intestinal sterol absorption and biliary excretion [33]. Sterols are essential constituents of cellular membranes in human, animals and plants. In humans and animals, cholesterol is the sterol that is synthesised, absorbed and utilised, whereas plants do not synthesise cholesterol, but use molecules that are similar, such as sitosterol, campesterol and stigmasterol. Although similar amounts of cholesterol and plant sterols are present in the typical human diet, the intestine of normal subjects provides an efficient barrier against the absorption of the majority of plant sterols [3]. On average, $<1-5 \%$ of dietary plant sterols are absorbed and retained compared with $\sim 55 \%$ of dietary cholesterol $[3,34]$. Thus, in healthy individuals, there exists an exquisite mechanism that allows the body to distinguish between cholesterol and non-cholesterol sterols. ABCG5 and ABCG8 are two genes located adjacently in a head-to-head configura- 
Table 3: Sterol compositions in SD, Wistar, GH, WKY and SHR rats a

\begin{tabular}{rccccc}
\hline Tissues & Total sterol $\mathrm{mg} / \mathrm{dL}$ or $\mathrm{mg} / \mathrm{g}$ & Cholesterol $\mathrm{mg} / \mathrm{dL}(\%)$ & Campesterol $\mathrm{mg} / \mathrm{dL}(\%)$ & Sitosterol $\mathrm{mg} / \mathrm{dL}(\%)$ & Total plant sterol $\mathrm{mg} / \mathrm{dL}(\%)$ \\
\hline $\begin{array}{r}\text { Plasma } \\
\text { SD }\end{array}$ & & & & & \\
Wistar & 57.8 & $54.6(94.5)$ & $1.30(2.2)$ & $1.95(3.4)$ & $3.3(5.5)$ \\
GH & 96.3 & $92.0(95.5)$ & $1.90(2.0)$ & $2.40(2.49)$ & $4.3(4.47)$ \\
WKY & 88.9 & $84.0(94.5)$ & $2.24(2.5)$ & $2.62(2.54)$ & $4.9(5.47)$ \\
SHR & 76.5 & $63.4(82.9)$ & $4.40(5.8)$ & $8.65(11.3)$ & $13.1(17.1)$ \\
Liver & 68.6 & $58.3(85.0)$ & $4.00(5.8)$ & $6.25(9.11)$ & $10.3(15.0)$ \\
SD & 1.77 & $1.72(97.1)$ & & & $0.03(1.58))$ \\
Wistar & 1.62 & $1.55(95.4)$ & $0.03(1.4)$ & $0.04(2.47)$ & $0.05(2.99)$ \\
WKY & 2.33 & $2.10(90)$ & $0.04(2.2)$ & $0.14(6.05)$ & $0.08(4.60)$ \\
SHR & 2.06 & $1.85(90)$ & $0.09(4.1)$ & $0.12(5.83)$ & $0.24(10.0)$ \\
Brain & & & & & $0.21(9.95)$ \\
SD & 11.0 & $10.95(99.6)$ & $0.02(0.2)$ & $0.02(0.15)$ & $0.03(0.6)$ \\
Wistar & 13.8 & $13.73(99.5)$ & $0.02(0.1)$ & $0.04(0.31)$ & $0.06(0.45)$ \\
WKY & 12.2 & $12.15(99.6)$ & $0.02(0.2)$ & $0.03(0.25)$ & $0.05(0.40)$ \\
SHR & 11.8 & $11.76(99.7)$ & $0.02(0.2)$ & $0.01(0.05)$ & $0.03(0.25)$
\end{tabular}

a The rats $(n=2$ for SD, Wistar, WKY and SHR; $n=4$ for $G H)$ were II weeks old and in regular rodent chow diet.

tion on human chromosome 2p21, encoding for two halftransporters, sterolin 1 and sterolin 2 respectively $[9,10,12]$. Mutations in either of these genes causes sitosterolemia, characterized by hyperabsorption of phytosterols, reduced excretion of sterols into the bile and very elevated levels of plasma plant sterol levels. In sitosterolemic patients, the absorption of phytosterols in intestine is dramatically increased, with absorption of plant sterols to about the same extent $(\sim 60 \%)$ as cholesterol.

Interestingly, a similar whole-body accumulation of plant sterols, less severe than in human sitosterolemia, has been reported recently in SHR, SHRSP and WKY rats, but not in the other genetically related rat strains, such as SD, Wistar and WKA rats [16]. These rats exhibit defects at two levels: increased absorption of sterols (plant and animal) at the intestinal level and decreased excretion of sterols into bile [16]. The higher sterol absorption in the intestine and the lower biliary excretion of plant sterols in these rat strains led us to hypothesise that $A b c g 5$ or $A b c g 8$ gene mutations may be responsible for the sitosterolemia observed in these hypertensive rats.

Characterization of the rat STSL locus showed that it is highly conserved in organization, and maps to rat chromosome 6q12, a region also syntenic with the mouse and human STSL loci. Rat $A b c g 5$ and $A b c g 8$ are expressed in a tissue-specific manner, with expression confined to the liver and the intestine. We sequenced the STSL loci in sitosterolemic and control rat strains and identified a number of nucleotide changes. Most of these nucleotide changes were in intronic regions and, based upon their locations, are likely to be 'silent'. However, one change,
G1754T in exon 12 was identified that led to a coding change of Gly583Cys in sterolin-1 (Abcg5). This change was found only in rat strains that were confirmed to be sitosterolemic (WKY, SHR and SHRSP), but not in any of the other strains screened (SD, Wistar, WKA, GH or BN).

The significance of other genetic variances in $A b c g 5$ and Abcg8 in different rat strains documented in this study is presently unknown. Plant sterol metabolism has been extensively evaluated in different rat strains, but the accumulation of plant sterols occurs only in SHR, SHRSP and WKY rats. The predicted 6 trans-membrane domain model of sterolin-1 indicates that the Gly583Cys missense mutation is located within the third extracellular loop (residues 554-620), in a conserved region (Fig 5C) and is adjacent to two potential $\mathrm{N}$-glycosylation sites (residues 585 and 594). Thus a mutation at residue 583 could disrupt the first site. Finally, both the sterolin- 1 and sterolin2 are cysteine-rich proteins (16 cysteines in sterolin 1 and 14 in sterolin 2), five of these cyteines in sterolin-1 are present in the extracellular loop containing the mutation. It is tempting to speculate that the gain of an additional cysteine in sterolin-1 by the Gly583Cys missense mutation might affect intracellular trafficking or the heterodimerization with sterolin-2. This possibility is diminished but not eliminated by the demonstration that in both the mutant and control rats, Abcg5 is located apically in the intestine (Fig. 9). Evidence that sterolin-1 and sterolin-2 may heterodimerize has now been presented, based upon in vitro analyses [13]. However, our preliminary analyses of immunohistochemistry, using an antibody to sterolin-1 suggests that the pattern of expression in the liver and intestine is similar for both SD as well as 
Table 4: Polymorphic changes at the STSL locus identified in different rat strains

\begin{tabular}{|c|c|c|c|c|c|c|c|c|c|}
\hline Gene & Position & Nucleotide change $^{a}$ & Effect $^{\mathbf{b}}$ & Wistar & WKA & WKY & SHR & SHRSP & GH \\
\hline \multirow[t]{24}{*}{ Abcg5 } & 5'-UTR & $-99 A>G$ & - & $\pm \sqrt{ }$ & & & & & \\
\hline & Intron I & IVSI-8delC & - & & $\sqrt{ }$ & $\sqrt{ }$ & $\sqrt{ }$ & $\sqrt{ }$ & $\sqrt{ }$ \\
\hline & & IVSI-95 A>C & - & & $\sqrt{ }$ & $\sqrt{ }$ & $\sqrt{ }$ & $\sqrt{ }$ & $\sqrt{ }$ \\
\hline & & IVSI-258 A>G & - & & $\sqrt{ }$ & $\sqrt{ }$ & $\sqrt{ }$ & $\sqrt{ }$ & $\sqrt{ }$ \\
\hline & Intron3 & IVS3+14 T>C & - & & $\sqrt{ }$ & $\sqrt{ }$ & $\sqrt{ }$ & $\sqrt{ }$ & \\
\hline & Intron4 & IVS4+86 T>C & - & & $\sqrt{ }$ & $\sqrt{ }$ & $\sqrt{ }$ & $\sqrt{ }$ & \\
\hline & Intron5 & IVS5+70 A>G & - & $\sqrt{ }$ & $\sqrt{ }$ & & & & $\sqrt{ }$ \\
\hline & & IVS5-90 C>T & - & & $\sqrt{ }$ & $\sqrt{ }$ & $\sqrt{ }$ & $\sqrt{ }$ & \\
\hline & Intron6 & IVS6+64 C>T & - & & & $\sqrt{ }$ & $\sqrt{ }$ & $\sqrt{ }$ & \\
\hline & Exon7 & $856 \mathrm{C}>\mathrm{T}$ & G283G & & & $\sqrt{ }$ & $\sqrt{ }$ & $\sqrt{ }$ & \\
\hline & Exon8 & $106 \mid C>T$ & L352L & $\pm \sqrt{ }$ & $\sqrt{ }$ & $\sqrt{ }$ & $\sqrt{ }$ & $\sqrt{ }$ & $\sqrt{ }$ \\
\hline & Intron8 & IVS8+10 delC & - & & $\sqrt{ }$ & $\sqrt{ }$ & $\sqrt{ }$ & $\sqrt{ }$ & \\
\hline & & IVS8-|7| C>T & - & & & & & & $\sqrt{ }$ \\
\hline & Exon9 & $1265 \mathrm{C}>\mathrm{T}$ & $\mathrm{R} 420 \mathrm{R}$ & $\sqrt{ }$ & $\sqrt{ }$ & $\sqrt{ }$ & $\sqrt{ }$ & $\sqrt{ }$ & $\sqrt{ }$ \\
\hline & & $1288 T>C$ & L427L & & & $\sqrt{ }$ & $\sqrt{ }$ & $\sqrt{ }$ & $\sqrt{ }$ \\
\hline & Intron 10 & IVSI0+60A>G & - & & $\sqrt{ }$ & $\sqrt{ }$ & $\sqrt{ }$ & $\sqrt{ }$ & $\sqrt{ }$ \\
\hline & & IVSI0+97 G>C & - & & $\sqrt{ }$ & $\sqrt{ }$ & $\sqrt{ }$ & $\sqrt{ }$ & $\sqrt{ }$ \\
\hline & & IVSI0+99 G>T & - & & & & & & $\sqrt{ }$ \\
\hline & Intron II & IVSII $+24 T>G$ & - & & & & $\sqrt{ }$ & $\sqrt{ }$ & \\
\hline & & IVSII+33 delG & - & & & & $\sqrt{ }$ & $\sqrt{ }$ & \\
\hline & Exon 12 & I 754 G > T & G583C & & & $\sqrt{ }$ & $\sqrt{ }$ & $\sqrt{ }$ & \\
\hline & 3'-UTR & $* 25 \mathrm{I} T>\mathrm{C}$ & - & $\pm \sqrt{ }$ & & & & & \\
\hline & & $* 26 \mid \mathrm{C}>\mathrm{T}$ & - & $\pm \sqrt{ }$ & & & & & \\
\hline & & $* 353 \mathrm{C}>\mathrm{A}$ & - & $\pm \sqrt{ }$ & $\sqrt{ }$ & $\sqrt{ }$ & $\sqrt{ }$ & $\sqrt{ }$ & \\
\hline \multirow[t]{14}{*}{ Abcg8 } & Intron I & $\mid V S I+399 A>C$ & - & $\pm \sqrt{ }$ & $\sqrt{ }$ & $\sqrt{ }$ & $\sqrt{ }$ & $\sqrt{ }$ & \\
\hline & & $I V S I+558 C>A$ & - & & & $\sqrt{ }$ & $\sqrt{ }$ & $\sqrt{ }$ & \\
\hline & & IVSI-53 A>G & - & $\pm \sqrt{ }$ & $\sqrt{ }$ & $\sqrt{ }$ & $\sqrt{ }$ & $\sqrt{ }$ & $\sqrt{ }$ \\
\hline & Intron 6 & IVS6-34 G>A & - & & & $\sqrt{ }$ & $\sqrt{ }$ & $\sqrt{ }$ & \\
\hline & Intron 9 & IVS9+13 C>T & - & $\pm \sqrt{ }$ & & $\sqrt{ }$ & $\sqrt{ }$ & $\sqrt{ }$ & $\sqrt{ }$ \\
\hline & & IVS9+75 C>T & - & & $\sqrt{ }$ & & & & \\
\hline & 3'-UTR & $*|0| \mathrm{C}>\mathrm{T}$ & - & $\pm \sqrt{ }$ & & $\sqrt{ }$ & $\sqrt{ }$ & $\sqrt{ }$ & \\
\hline & & $*|46| A>G$ & - & $\pm \sqrt{ }$ & & $\sqrt{ }$ & $\sqrt{ }$ & $\sqrt{ }$ & \\
\hline & & $* \mid 458 \mathrm{~T}>\mathrm{C}$ & - & $\pm \sqrt{ }$ & & $\sqrt{ }$ & $\sqrt{ }$ & $\sqrt{ }$ & $\sqrt{ }$ \\
\hline & & *1777_I778insAGG & - & & & $\sqrt{ }$ & $\sqrt{ }$ & $\sqrt{ }$ & \\
\hline & & $*|78| \mathrm{T}>\mathrm{G}$ & - & & & $\sqrt{ }$ & $\sqrt{ }$ & $\sqrt{ }$ & $\sqrt{ }$ \\
\hline & & $* 1799 \mathrm{~A}>\mathrm{G}$ & - & $\pm \sqrt{ }$ & & $\sqrt{ }$ & $\sqrt{ }$ & $\sqrt{ }$ & \\
\hline & & $* 1967 \mathrm{G}>\mathrm{T}$ & - & $\pm \sqrt{ }$ & & $\sqrt{ }$ & $\sqrt{ }$ & $\sqrt{ }$ & \\
\hline & & *2099_2100ins I43 nt & - & $\pm \sqrt{ }$ & & $\sqrt{ }$ & $\sqrt{ }$ & $\sqrt{ }$ & $\sqrt{ }$ \\
\hline
\end{tabular}

$\pm \sqrt{ }$ indicates for heterozygous, $\sqrt{ }$ for homozygous a Numbering based as indicated in Table $I$, see Additional file $I^{\mathrm{b}}$ Numbering based upon the first ATG as +I All sequences are same as that of Sprague Dawley, unless indicated by the check mark. Sequence in bold indicates the coding change.

WKY or SHR rats (Fig. 9). These studies are limited in scope, as antibody reagents to detect rat sterolin-2 are not currently available.

Another formal possibility not excluded is that the Gly583Cys missense mutation may have no significance in the accumulation of phytosterols in WKY, SHR and SHRSP, and that the alteration in the 3' UTR or even the intronic changes reported above may be the causative 'mutations'. Our analyses of the mRNA and protein profiles would not strongly support these possibilities. However, further investigation will be required to determine if the 3-base insertion in the predicted 3'UTR of Abcg8 has any functional consequence. In the absence of a direct assay for sterolin-1 and -2 function, the genetic changes presented, together with the correlation of the phenotypes, remains the strongest evidence that these genetic alterations are functional, and that the Gly583Cys is a mutational change.

A more relevant question raised in this study is whether the plant sterol accumulation in hypertensive rat strains has significance in the pathophysiology of hypertension. Recent linkage mapping studies mapped hypertension 
A

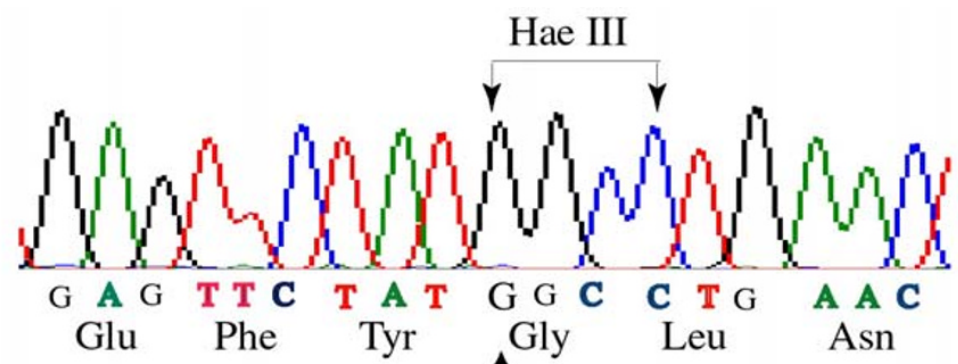

SD, Wistar WKA, GH, BN

KY, SHR SHRSP

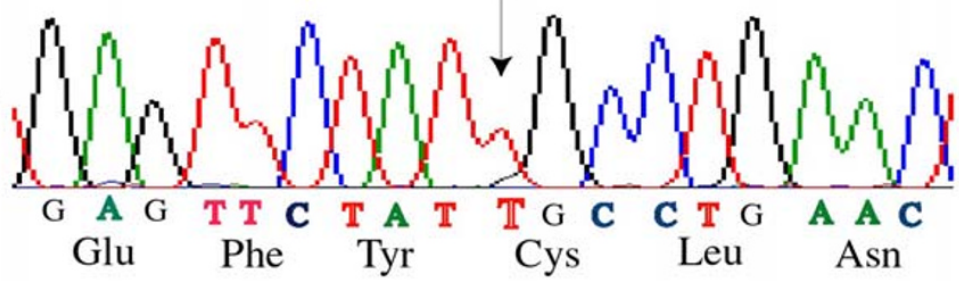

B

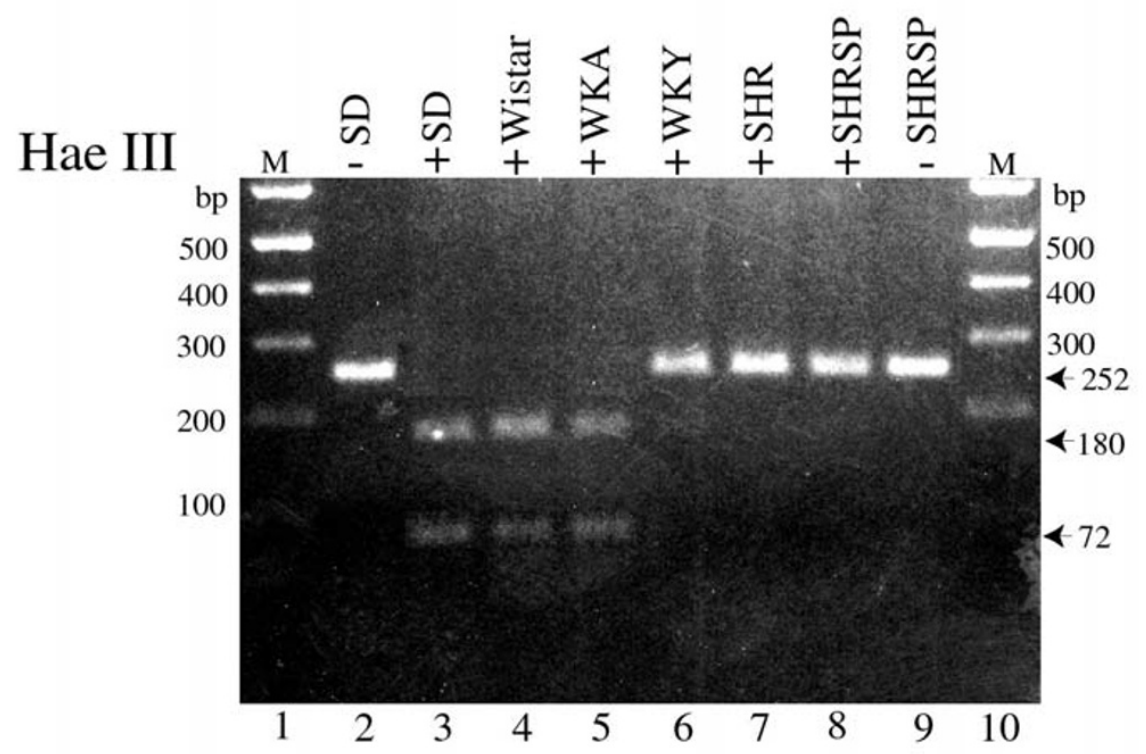

C

\begin{tabular}{|c|c|c|}
\hline & Y F T F & \\
\hline & 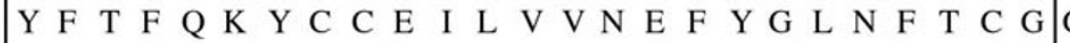 & \\
\hline & 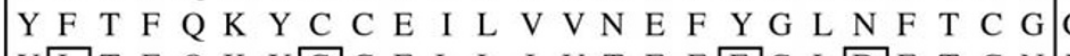 & \\
\hline & 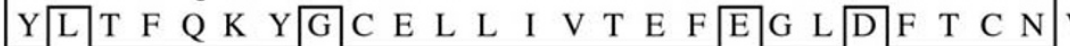 & \\
\hline
\end{tabular}

Figure 5

Demonstration of G I754T (Gly583Cys) mutation in SHR, SHRSP and WKY rats. Panel A shows a representative sequence electropherogram from SD, Wistar, WKA, GH and BN rats (top electropherogram) and from SHR, SHRSP and WKY rats (bottom electropherogram) for exon 12 of Abcg5. A homozygous change (GI754T, Gly583Cys) is present in the sitosterolemic rats and this mutation abolishes the recognition site for restriction enzyme Hae III. Panel B shows the restriction fragment analyses of DNA amplified from these different rat strains, further confirming the presence of the mutational change. In the absence of digestion a 252 bp PCR product is present, which, after Hae III digestion (wt) results in two products of 180 bp and 72 bp (indicated by the arrows). The sitosterolemic strains WKY, SHR and SHRSP (lanes 6-8) are all resistant to digestion by Hae III, but SD and Wistar remain sensitive (lanes 3 and 4). Lanes I and IO shows molecular weight markers, and lanes 2 and 9 show undigested PCR products ( $252 \mathrm{bP}$ ) from SD rat and SHRSP respectively. Panel C shows the alignment of amino acids 565 to 592 of sterolin-I from human, mouse, rat and Fugu. An arrowhead indicates the position of Gly583Cys mutation. 


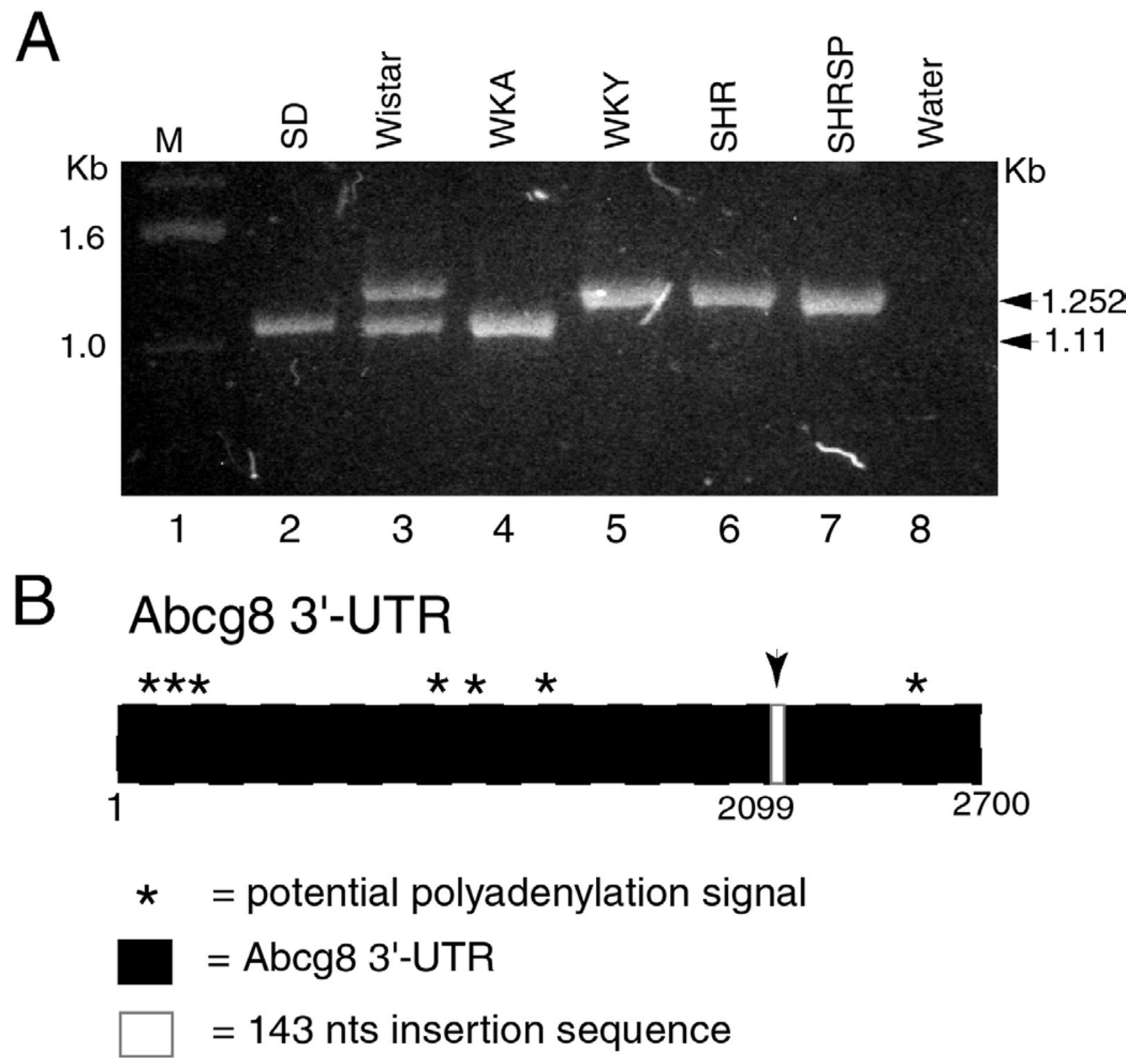

\section{Figure 6}

Insertional polymorphisms in rat Abcg8 exon 13. Panel A shows the sizes of PCR products amplified using primers that amplify the 3'-UTR of Abcg8. Two distinct products of I.II Kb and I.252 Kb bands were noted. SD and WKA were homozygous for the I.I I kb size, while WKY, SHR and SHRSP were homozygous for the I.25 kb size. Interestingly, the sample from a Wistar rat was heterozygous for this change. Direct sequencing of the larger product showed a I43 bp insertion at position 2099 in the 3' UTR of Abcg8 (panel B).

QTLs to a number of chromosomal regions in SHR and SHRSP rats [35]. Our FISH study assigned the STSL locus rat chromosome 6q12, a region where a cluster of blood pressure QTL with Lod score $4 \sim 6$ has been reported to be present (M6MIT12-M6MIT3, $39 \mathrm{cM}$ distance) in a New Zealand genetically hypertensive rat (GH rat) [35]. With respect to hypertension, although the SHR and SHRSP strains carry the Gly583Cys mutation, in extensive QTL 


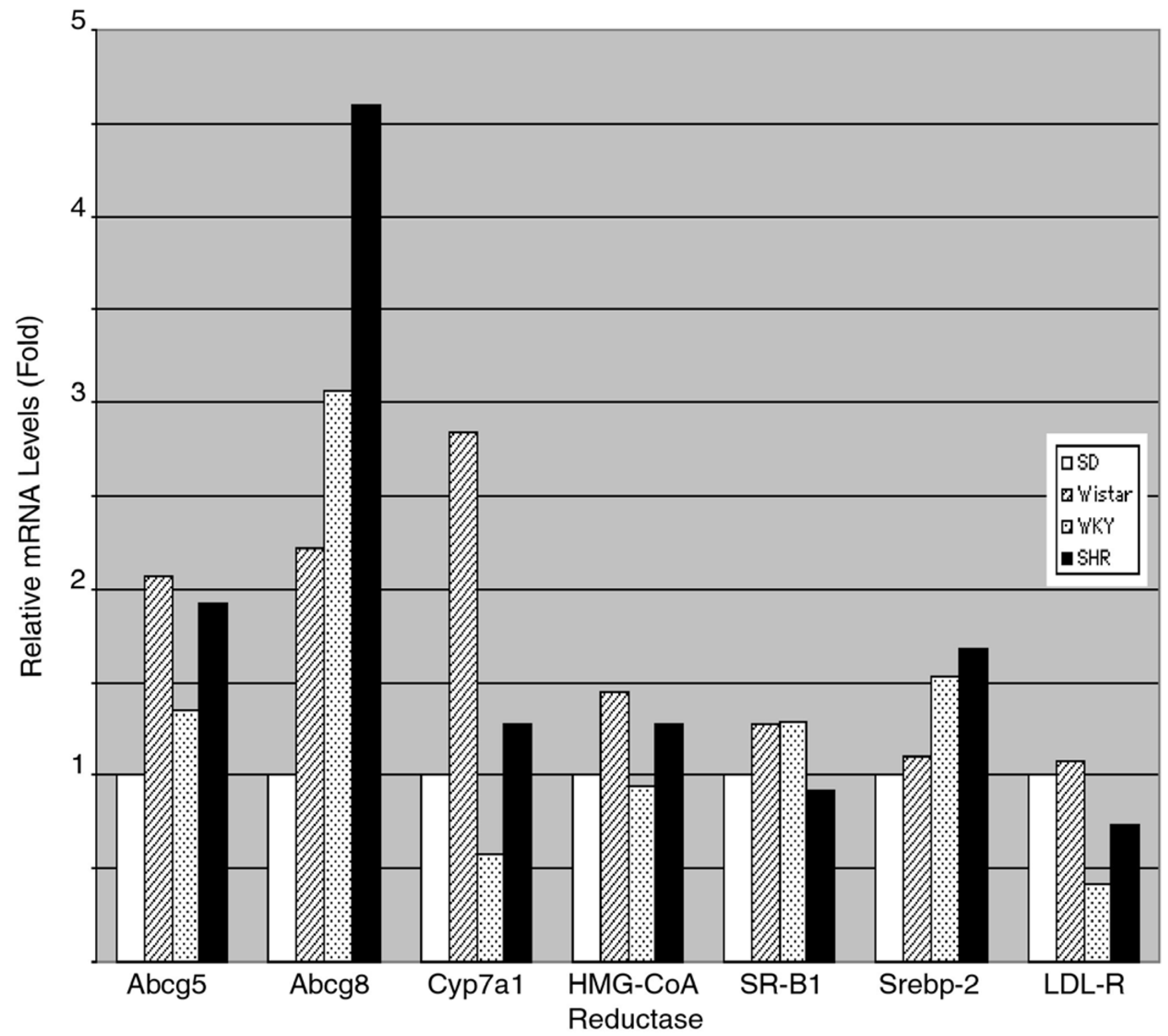

Figure 7

Real time PCR quantification of selected rat mRNAs. Real time PCR and quantitation of message abundance was performed as described in Methods. Relative to the levels in livers from SD rats, expression of mRNAs for both sterolins was increased 3-5 fold in the SHR livers, as was the message for Srebp-2 ( 2 fold). No significant change in SR-BI or Cyp7a I for SHR compared to SD liver RNAs was noted. However, the expression of LDL-R was reduced in both WKY and SHR rats.

mapping studies using these strains, no loci mapping to the rat STSL region have been reported [35]. In our study, the GH rat is neither sitosterolemic, nor has any nucleotide alteration at the STSL locus that would implicate this region as mutated. Thus we do not believe the STSL locus plays a role in determining blood pressure. How- ever, it may play a significant role in modifying the pathophysiology.

Studies reported by different investigators have shown that a dietary intake of $10 \%$ canola oil (as part of semipurified diets) significantly shortened the life-span of SHRSP rats, with accumulation of phytosterols in plasma, 


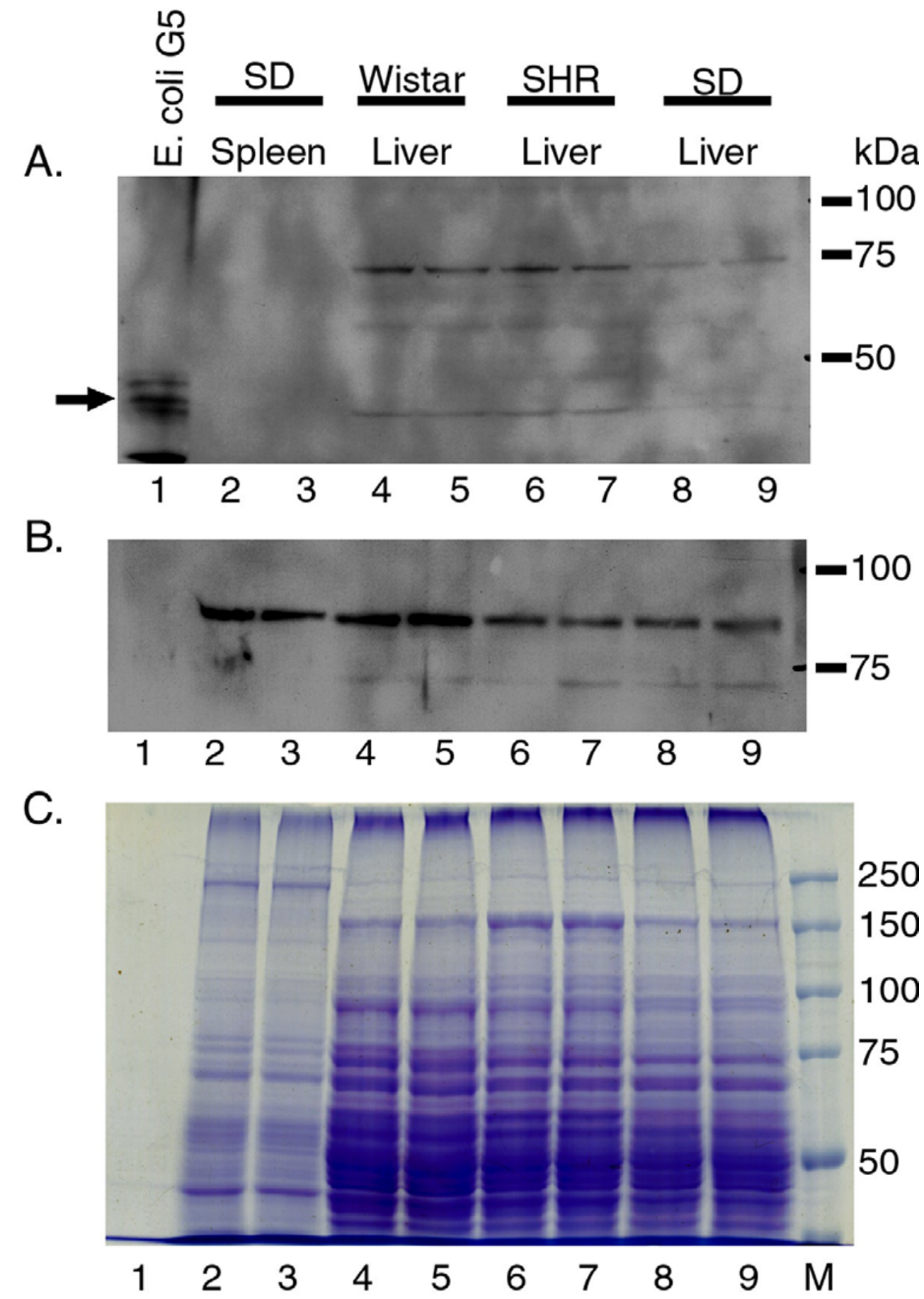

Figure 8

Protein Expression of $\mathbf{A b c g} 5$ in liver total membrane preparations. Membrane preparations (20 $\mu \mathrm{g}$ protein) from rat tissues were isolated and analysed by SDS-PAGE, blotted and probed with anti-Abcg5 antiserum (RII6, panel A), probed with anti-transferrin antiserum (panel B) or the gel was fixed and stained with Coomassie Brilliant Blue R-250 (panel C). Lane I contains a recombinant $E$. coli expressed $N$-terminal fragment of sterolin-I as a control for antibody binding, lanes 2 and 3 contain Sprague-Dawley (SD) spleen membrane extracts. Liver from Wistar (lanes 4 and 5), SHR (lanes 6 and 7 ) and Sprague-Dawley (SD, lanes 8 and 9) Densitometry measurements when normalised to transferrin show a 2-fold increase in sterolin-I protein in SHR rat liver samples, compared to SD and Wistar rat liver. No antibody for sterolin-2 is currently available. 


\section{A. Pre immune}
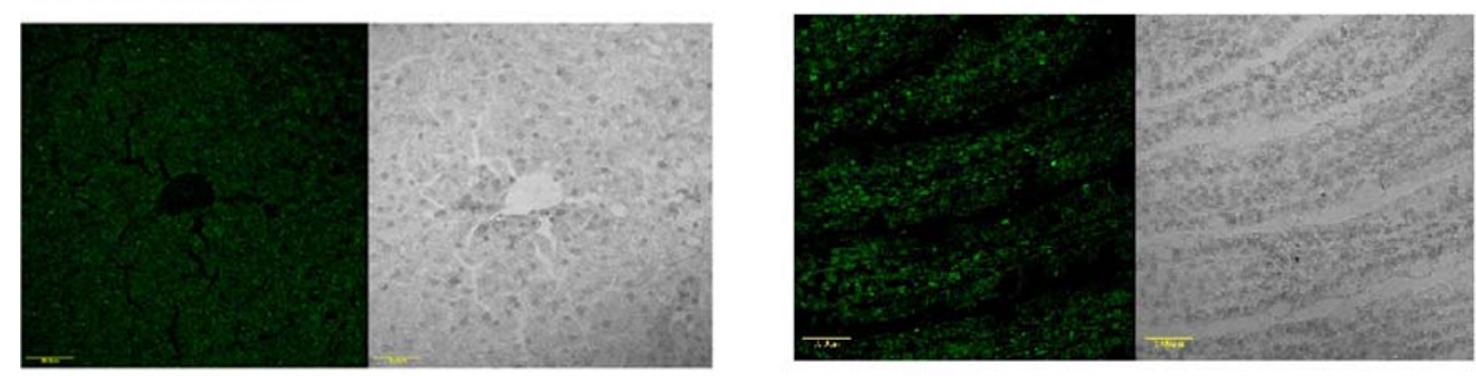

B. Wistar
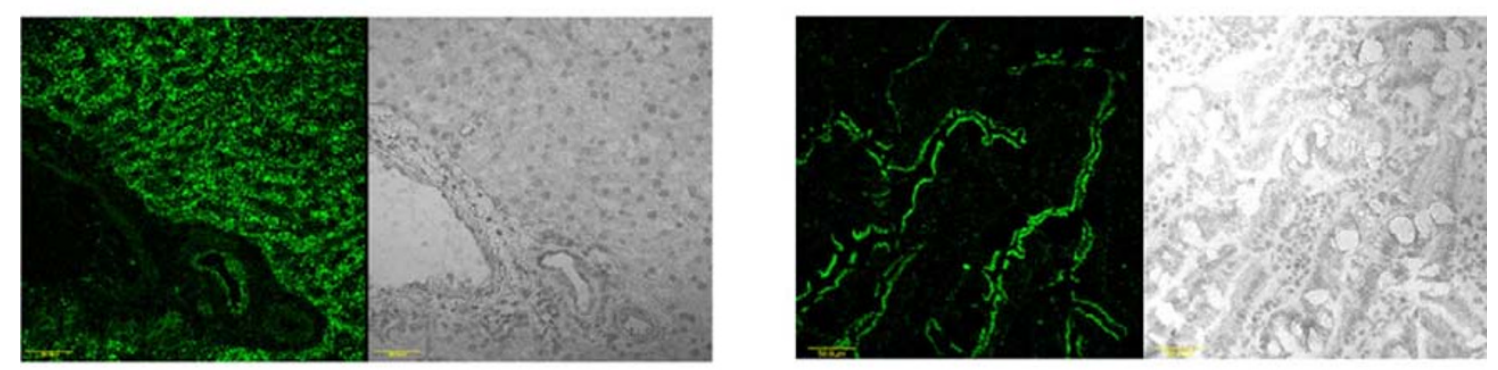

\section{WKY}
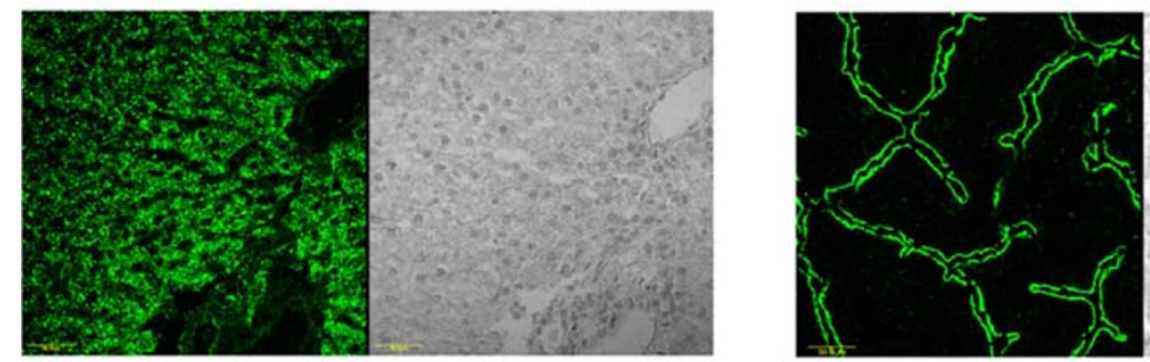

\section{SHR}

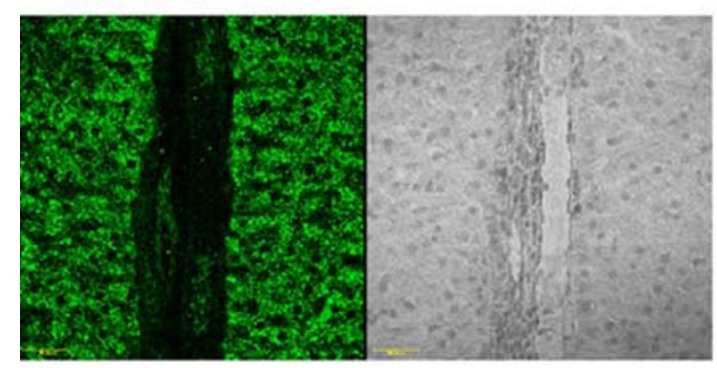

Liver

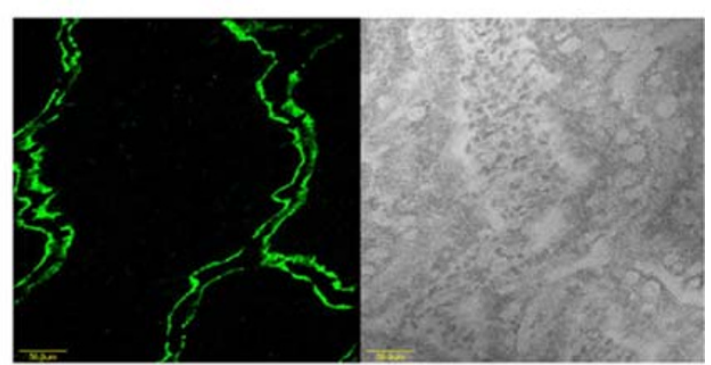

Intestine

Figure 9

Immunohistochemical detection of Abcg5 in liver and intestine from different rat strains. The panels on the left hand show liver sections and those on the right hand show intestinal sections. The right hand images of each panel show the hematoxylin stained images, viewed with transmitted light and the left hand images show the fluorescence images captured at the same laser wavelength and intensity. Panel A shows results obtained with the pre-immune serum, panel B, $C$ and $D$ the results for Wistar, WKY and SHR rat tissues. All sections were captured at $40 \times$ magnification. Scale bars $(50 \mu \mathrm{m})$ are shown in the bottom left hand corner of each image. The data for SD rat tissues were similar to those obtained with Wistar and are not shown. 
red blood cells and tissues [15,17-19,21,22]. Lower red blood cell (RBC) membrane deformability, lower density of platelets, as well as a higher blood pressure were also observed, when compared to a SHRSP group fed with vegetable oils lower in phytosterols $(10 \%$ soybean oil vs. $10 \%$ canola oil). Canola oil has a higher sitosterol content than soybean oil. In comparison, extensive studies on evaluation of high phytosterol diets in SD rats (non-sitosterolemic) have consistently shown to be safe without any adverse consequences [36-42]. These intriguing differences between SHRSP and SD rats may now be explained, at least in part, by presence of the Gly583Cys missense mutation in sterolin-1. The WKY rat also carries this mutation and a high dietary intake of phytosterols will also increase the blood pressure and decrease the density of platelets, though to a lower extent than that observed in SHRSP rats [20]. These data support a pathological role of elevated plant sterols in these rats and support the notion that the STSL loci evolved to not only allow for the excretion of cholesterol into bile, but also to keep 'xeno-sterols' from accumulating in the body. With respect to sitosterolemia in humans, although atherosclerotic complications have been well-described, hypertension has not been mentioned as feature. However, it is not known whether the atherosclerosis in sitosterolemic patients with hypertension is accelerated, relative to those affected individuals with lower blood pressures.

The Gly583Cys mutation in Abcg5 is likely to have originated in the original outbred Wistar colony bred in Kyoto (from which WKY was subsequently derived), which has been widely employed as a normotensive control in experimental studies of hypertension. It gave rise to the SHR and SHRSP strains. Thus, this mutation in WKY, SHR and SHRSP lines may not contribute to the hypertension phenotype per se, but may only be responsible for sitosterolemia. The original Wistar colony was established at the Wistar Institute in 1906, and the Sprague Dawley colony was derived by Dawley in approximately 1925 from a single male of unknown origin and a Wistar female. The SHR strain was derived by selective inbreeding from the Kyoto outbred Wistar colony, and both SHR and SHRSP, as well as WKY strains have been maintained over many generations through brother-sister matings http://rgd.mcw.edu/tools/strains [43,44]. Healthy WKA and GH rat strains were also generated from outbred Wistar rat strains, but these strains were isolated independently in Japan and New Zealand, respectively (and maintained at other sites as well). The GH rat was selected for systolic hypertension that increased with successive generations and maintained through filial matings [45]. In view of this, the Gly583Cys missense mutation of Abcg5 might result from occurrence of a de novo mutation during breeding at the stage of developing inbred WKY strains and propagated into the SHR and SHRSP lines. In contrast, the 143 nucleotide fragment insertion polymorphism in the 3'-UTR of Abcg8 may have resulted from acquisition of a foreign chromosomal fragment during the Wistar rat strain breeding and established as homozygous change in the WKY, SHR and SHRSP, as well as GH rat strains. In this context, it is important to note that 3 other mutant loci have been reported in the SHR rat; missense mutations in the KAT-1 (kynurenine aminotransferase-1), Srebf-1 (sterol regulatory element binding factor-1) and CD36 (fatty acid translocase) are all present as homozygous changes [46-48]. The generation of congenic lines may assist with addressing many of these issues. Such lines will be useful in demonstrating that the variant sterolin-1 protein is responsible for causing sitosterolemia, but will allow comparisons between animals that are hypertensive and those that are hypertensive and sitosterolemic. Currently, there are no appropriate genetic controls available, as SHR, SHRSP and WKY are all maintained as colonies by brother-sister matings. While this manuscript was in review, Scoggan et al also reported identifying Gly583Cys alteration in Abcg5 of SHR, SHRP and WKY rats [49].

\section{Conclusion}

Three rat strain, WKY, SHR and SHRSP, that are hypertensive are also sitosterolemic. All of these strains are homozygous mutant for Gly583Cys in sterolin-1, encoded by Abcg5. This mutation is not present in rats that were not sitosterolemic, even though one of these was hypertensive (the GH rat). The rat STSL locus, comprising of $A b c g 5$ and $A b c g 8$, maps to rat chromosome 6q12, a region syntenic with both mouse and human STSL loci. Preliminary antibody studies show that this mutant protein is expressed and appears to be apically targeted in the intestinal cells.

\section{Competing Interests}

None declared.

\section{Authors' contributions}

HY conceived this study, HY, BP, and KL performed the molecular genetic studies, EK performed the real time PCR and the western blotting assays, M-HL performed the immunostaining, KH performed the FISH assay, RK and $\mathrm{AB}$ performed the sterol analyses, MS and NE performed the DNA isolations from the rats. HY, GS, IK, TR and SBP were responsible for supervision, and data analyses of the experiments, as well as for providing the funding. HY and SBP wrote the paper. All authors read and approved the final manuscript. 


\section{Additional material}

\section{Additional File 1}

Table 1 shows the primer sequences used for PCR amplification of genomic fragement of the rat STSL region.

Click here for file

[http://www.biomedcentral.com/content/supplementary/14712261-3-4-S1.doc]

\section{Acknowledgements}

We thank Dr. Jean Harris, University of Otago, New Zealand, for providing us with the DNA samples from GH and BN rats for this study, Drs. Howard Jacobs and Marijo Bilusic, Medical College of Wisconsin, Milwaukee, WI for plasma samples from $\mathrm{GH}$ rats (funded by the NHLBI Programs for Genomic Applications, UOI HL6657) and John Oatis IIIrd for providing technical assistance and animal husbandry. We also gratefully acknowledge the assistance of Dr. Thomas Ried in performing the FISH analyses.

\section{References}

I. Bjorkhem I and Boberg KM: Inborn errors in bile acid biosynthesis and storage of sterols other than cholesterol The Metabolic Basis of Inherited Disease Volume 2. 7thth edition. Edited by: Scriver CR, Beaudet AL, Sly WS and Valle D. New York, McGraw-Hill Inc.; I99520732102.

2. Salen G, Shefer S, Nguyen L, Ness GC, Tint GS and Shore V: Sitosterolemia. Journal of Lipid Research 1992, 33:945-955.

3. Gould RG, Jones RJ, LeRoy GV, Wissler RW and Taylor CB: Absorbability of beta-sitosterol in humans Metabolism 1969, 18:652662.

4. Bhattacharyya AK and Connor WE: Beta-sitosterolemia and xanthomatosis. A newly described lipid storage disease in two sisters Journal of Clinical Investigation 1974, 53:1033-1043.

5. Gregg RE, Connor WE, Lin DS and Brewer Hb, Jr.: Abnormal metabolism of shellfish sterols in a patient with sitosterolemia and xanthomatosis Journal of Clinical Investigation 1986, 77:1864-1872

6. Salen G, Shore V, Tint GS, Forte T, Shefer S, Horak I, Horak E, Dayal $B$, Nguyen L, Batta AK and et al: Increased sitosterol absorption, decreased removal, and expanded body pools compensate for reduced cholesterol synthesis in sitosterolemia with xanthomatosis Journal of Lipid Research 1989, 30:1319-1330.

7. Bhattacharyya AK, Connor WE, Lin DS, McMurry MM and Shulman RS: Sluggish sitosterol turnover and hepatic failure to excrete sitosterol into bile cause expansion of body pool of sitosterol in patients with sitosterolemia and xanthomatosis Arteriosclerosis \& Thrombosis | 991, I I: |287-I 294.

8. Patel SB, Salen G, Hidaka H, Kwiterovich PO, Stalenhoef AF, Miettinen TA, Grundy SM, Lee MH, Rubenstein JS, Polymeropoulos MH and Brownstein MJ: Mapping a gene involved in regulating dietary cholesterol absorption. The sitosterolemia locus is found at chromosome 2p2 I / Clin Invest 1998, 1 02: 104 I- 1044.

9. Berge KE, Tian H, Graf GA, Yu L, Grishin NV, Schultz J, Kwiterovich P, Shan B, Barnes R and Hobbs HH: Accumulation of dietary cholesterol in sitosterolemia caused by mutations in adjacent ABC transporters Science 2000, 290: I77I-I775.

10. Lee M-H, Lu K, Hazard S, Yu H, Shulenin S, Hidaka H, Kojima H, Allikmets R, Sakuma N, Pegoraro R, Srivastava AK, Salen G, Dean M and Patel SB: Identification of a gene, ABCG5, important in the regulation of dietary cholesterol absorption Nature Genetics 200I, 27:79-83.

II. Lu K, Lee M-H, Carpten JD, Sekhon M and Patel SB: High-Resolution Physical and Transcript Map of Human Chromosome 2p2 I Containing the Sitosterolemia Locus European Journal of Human Genetics 200I, 9:364-374.

12. Lu K, Lee M-H, Hazard S, Brooks-Wilson A, Hidaka H, Kojima H, Ose L, Stanlenhoef AFH, Mietinnen T, Bjorkhem I, Brukert E, A. Pandya., Brewer HB, Salen G, Dean M, Srivastava A and Patel SB: Two genes that map to the STSL locus cause sitosterolemia: Genomic structure and spectrum of mutations involving sterolin-I and sterolin-2, encoded by ABCG5 and ABCG8 respectively American Journal of Human Genetics 2001, 69:278-290.

13. Graf GA, Li WP, Gerard RD, Gelissen I, White A, Cohen JC and Hobbs $\mathrm{HH}$ : Coexpression of ATP-binding cassette proteins ABCG5 and ABCG8 permits their transport to the apical surface I Clin Invest 2002, I I 0:659-669.

14. Lu K, Lee MH, Yu H, Zhou Y, Sandell SA, Salen G and Patel SB: Molecular cloning, genomic organization, genetic variations, and characterization of murine sterolin genes Abcg5 and Abcg8 J Lipid Res 2002, 43:565-578.

15. Ratnayake WM, Plouffe L, Hollywood R, L'Abbe MR, Hidiroglou N, Sarwar $G$ and Mueller R: Influence of sources of dietary oils on the life span of stroke-prone spontaneously hypertensive rats Lipids 2000, 35:409-420.

16. Ikeda I, Nakagiri H, Sugano M, Ohara S, Hamada T, Nonaka M and Imaizumi K: Mechanisms of phytosterolemia in stroke-prone spontaneously hypertensive and WKY rats Metabolism 200I, 50:136I-1368.

17. Huang MZ, Naito $Y$, Watanabe $S$, Kobayashi T, Kanai H, Nagai $\mathrm{H}$ and Okuyama $\mathrm{H}$ : Effect of rapeseed and dietary oils on the mean survival time of stroke- prone spontaneously hypertensive rats Biol Pharm Bull 1996, 19:554-557.

18. Huang MZ, Watanabe S, Kobayashi T, Nagatsu A, Sakakibara J and Okuyama $\mathrm{H}$ : Unusual effects of some vegetable oils on the survival time of stroke- prone spontaneously hypertensive rats Lipids 1997, 32:745-75I.

19. Ratnayake WM, L'Abbe MR, Mueller R, Hayward S, Plouffe L, Hollywood R and Trick K: Vegetable oils high in phytosterols make erythrocytes less deformable and shorten the life span of stroke-prone spontaneously hypertensive rats J Nutr 2000, 130:1166-1178

20. Naito $\mathrm{Y}, \mathrm{Kasama} \mathrm{K}$, Yoshida $\mathrm{H}$ and Ohara N: Thirteen-week dietary intake of rapeseed oil or soybean oil as the only dietary fat in Wistar Kyoto rats-change in blood pressure Food Chem Toxicol 2000, 38:8I I-8I6.

21. Naito Y, Yoshida H, Nagata T, Tanaka A, Ono H and Ohara N: Dietary intake of rapeseed oil or soybean oil as the only fat nutrient in spontaneously hypertensive rats and Wistar Kyoto rats - blood pressure and pathophysiology Toxicology 2000, 146: 197-208.

22. Naito $\mathrm{Y}$, Konishi $\mathrm{C}$ and Ohara N: Blood coagulation and osmolar tolerance of erythrocytes in stroke-prone spontaneously hypertensive rats given rapeseed oil or soybean oil as the only dietary fat Toxicol Lett 2000, I | 6:209-2 I5.

23. Islam $M Q$ and Levan $\mathrm{G}$ : A new fixation procedure for quality $\mathbf{G}$ bands in routine cytogenetic work Hereditas 1987, 107:127-130.

24. Pinkel D, Gray JW, Trask B, van den Engh G, Fuscoe J and van Dekken $\mathrm{H}$ : Cytogenetic analysis by in situ hybridization with fluorescently labeled nucleic acid probes Cold Spring Harb Symp Quant Biol I986, 5I:I5I-I57.

25. Helou K, Walter L, Gunther E and Levan G: Cytogenetic orientation of the rat major histocompatibility complex (MHC) on chromosome 20 Immunogenetics 1998, 47:166-169.

26. Wu J, Zhu YH and Patel SB: Cyclosporin-induced dyslipoproteinemia is associated with selective activation of SREBP-2 Am J Physiol 1999, 277:El 087-94.

27. Yang J, Goldstein JL, Hammer RE, Moon YA, Brown MS and Horton JD: Decreased lipid synthesis in livers of mice with disrupted Site-I protease gene Proc Natl Acad Sci U S A 200I, 98:13607$136 \mid 2$.

28. Plosch T, Kok T, Bloks VW, Smit MJ, Havinga R, Chimini G, Groen $A K$ and Kuipers F: Increased hepatobiliary and fecal cholesterol excretion upon activation of the liver $X$ receptor is independent of ABCAI J Biol Chem 2002, 277:33870-33877.

29. Thompson JD, Higgins DG and Gibson TJ: CLUSTAL W: improving the sensitivity of progressive multiple sequence alignment through sequence weighting, position-specific gap penalties and weight matrix choice Nucleic Acids Res 1994, 22:4673-4680.

30. Helou K, Walentinsson A, Levan $G$ and Stahl F: Between rat and mouse zoo-FISH reveals 49 chromosomal segments that have been conserved in evolution Mamm Genome 200 I, I 2:765771 .

31. Karlsson A, Helou K, Walentinsson A, Hedrich HJ, Szpirer $C$ and Levan G: Amplification of Mycn, DdxI, Rrm2, and Odcl in rat 
uterine endometrial carcinomas Genes Chromosomes Cancer 200I, 3 I:345-356.

32. Nilsson S, Helou K, Walentinsson A, Szpirer C, Nerman O and Stahl F: Rat-mouse and rat-human comparative maps based on gene homology and high-resolution zoo-FISH Genomics 200I, 74:287-298.

33. Lu K, Lee M and Patel SB: Dietary cholesterol absorption; more than just bile Trends in Endocrinology and Metabolism 200 I, I 2:314320.

34. Bosner MS, Lange LG, Stenson WF and Ostlund R. E., Jr.: Percent cholesterol absorption in normal women and men quantified with dual stable isotopic tracers and negative ion mass spectrometry J Lipid Res 1999, 40:302-308.

35. Stoll M, Kwitek-Black AE, Cowley A. W., Jr., Harris EL, Harrap SB, Krieger JE, Printz MP, Provoost AP, Sassard J and Jacob HJ: New target regions for human hypertension via comparative genomics Genome Res 2000, 10:473-482.

36. Waalkens-Berendsen DH, Wolterbeek AP, Wijnands MV, Richold M and Hepburn PA: Safety evaluation of phytosterol esters. Part 3. Two-generation reproduction study in rats with phytosterol esters--a novel functional food Food Chem Toxicol 1999, 37:683-696.

37. Weststrate JA, Ayesh R, Bauer-Plank C and Drewitt PN: Safety evaluation of phytosterol esters. Part 4. Faecal concentrations of bile acids and neutral sterols in healthy normolipidaemic volunteers consuming a controlled diet either with or without a phytosterol ester- enriched margarine Food Chem Toxicol 1999, 37: 1063-1071.

38. Hepburn PA, Horner SA and Smith M: Safety evaluation of phytosterol esters. Part 2. Subchronic $\mathbf{9 0 - d a y ~ o r a l ~ t o x i c i t y ~ s t u d y ~ o n ~}$ phytosterol esters--a novel functional food Food Chem Toxicol 1999, 37:521-532.

39. Ayesh R, Weststrate JA, Drewitt PN and Hepburn PA: Safety evaluation of phytosterol esters. Part 5. Faecal short-chain fatty acid and microflora content, faecal bacterial enzyme activity and serum female sex hormones in healthy normolipidaemic volunteers consuming a controlled diet either with or without a phytosterol ester- enriched margarine Food Chem Toxicol 1999, 37: | | $27-1138$

40. Sanders DJ, Minter HJ, Howes D and Hepburn PA: The safety evaluation of phytosterol esters. Part 6 . The comparative absorption and tissue distribution of phytosterols in the rat Food Chem Toxicol 2000, 38:485-49I.

41. Wasan KM, Peteherych KD, Najafi S, Zamfir C and Pritchard PH: Assessing the plasma pharmacokinetics, tissue distribution, excretion and effects on cholesterol pharmacokinetics of a novel hydrophilic compound, FM-VP4, following administration to rats J Pharm Pharm Sci 200I, 4:207-2I6.

42. Wolfreys AM and Hepburn PA: Safety evaluation of phytosterol esters. Part 7. Assessment of mutagenic activity of phytosterols, phytosterol esters and the cholesterol derivative, 4cholesten-3-one Food Chem Toxicol 2002, 40:46I-470.

43. Kurtz TW, Montano M, Chan L and Kabra P: Molecular evidence of genetic heterogeneity in Wistar-Kyoto rats: implications for research with the spontaneously hypertensive rat Hypertension 1989, 13:188-192.

44. St Lezin E, Simonet L, Pravenec M and Kurtz TW: Hypertensive strains and normotensive 'control' strains. How closely are they related? Hypertension 1992, 19:419-424.

45. Simpson FO, Phelan EL, Clark DW, Jones DR, Gresson CR, Lee DR and Bird DL: Studies on the New Zealand strain of genetically hypertensive rats Clin. Sci. Mol. Med. Suppl. 1973, 45 Suppl I:I5s21 .

46. Aitman TJ, Glazier AM, Wallace CA, Cooper LD, Norsworthy PJ, Wahid FN, Al-Majali KM, Trembling PM, Mann C), Shoulders CC, Graf D, St Lezin E, Kurtz TW, Kren V, Pravenec M, Ibrahimi A, Abumrad NA, Stanton LW and Scott J: Identification of Cd36 (Fat) as an insulin-resistance gene causing defective fatty acid and glucose metabolism in hypertensive rats Nat Genet 1999, 2 1:76-83.

47. Pravenec M, Jansa P, Kostka V, Zidek V, Kren V, Forejt J and Kurtz TW: Identification of a mutation in ADDI/SREBP-I in the spontaneously hypertensive rat Mamm Genome 200I, I 2:295298.

48. Kwok JB, Kapoor R, Gotoda T, Iwamoto Y, lizuka Y, Yamada N, Isaacs KE, Kushwaha VV, Church WB, Schofield PR and Kapoor V: A missense mutation in kynurenine aminotransferase-I in spontaneously hypertensive rats | Biol Chem 2002, 277:35779. 35782.

49. Scoggan KA, Gruber $\mathrm{H}$ and Lariviere $\mathrm{K}$ : A missense mutation in the Abcg5 gene causes phytosterolemia in SHR, strokeprone SHR, and WKY rats Journal of Lipid Research 2003, 44:91 I916.

\section{Pre-publication history}

The pre-publication history for this paper can be accessed here:

http://www.biomedcentral.com/1471-2261/3/4/prepub
Publish with Bio Med Central and every scientist can read your work free of charge

"BioMed Central will be the most significant development for disseminating the results of biomedical research in our lifetime. "

Sir Paul Nurse, Cancer Research UK

Your research papers will be:

- available free of charge to the entire biomedical community

- peer reviewed and published immediately upon acceptance

- cited in PubMed and archived on PubMed Central

- yours - you keep the copyright

Submit your manuscript here:

http://www.biomedcentral.com/info/publishing_adv.asp 